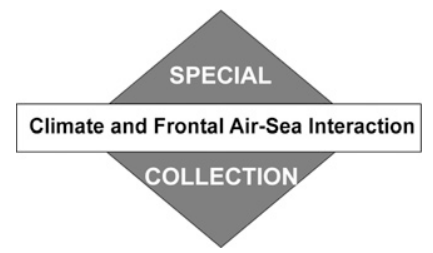

\title{
əProcesses Shaping the Frontal-Scale Time-Mean Surface Wind Convergence Patterns around the Gulf Stream and Agulhas Return Current in Winter
}

\author{
RYUSUKE MASUNAGA \\ International Pacific Research Center, University of Hawai`i at Mānoa, Honolulu, Hawaii \\ HISASHI NAKAMURA \\ Research Center for Advanced Science and Technology, The University of Tokyo, Tokyo, and Japan Agency for Marine- \\ Earth Science and Technology, Yokohama, Japan \\ BUNMEI TAGUCHI \\ Faculty of Sustainable Design, University of Toyama, Toyama, Japan \\ TAKAFUMI MIYASAKA \\ Japan Meteorological Business Support Center, and Meteorological Research Institute, Japan Meteorological Agency, \\ Tsukuba, and Research Center for Advanced Science and Technology, The University of Tokyo, Tokyo, Japan
}

(Manuscript received 16 December 2019, in final form 5 July 2020)

\begin{abstract}
High-resolution satellite observations and numerical experiments have revealed local enhancement of time-mean surface wind convergence along the axes of warm western boundary currents and divergence slightly poleward. A recent study has suggested that frequent occurrence of persistent atmospheric fronts and sea level pressure (SLP) troughs along a sea surface temperature (SST) front are responsible for shaping the frontal-scale wind convergence and divergence contrast as seen in the wintertime climatology near the Kuroshio Extension (KE). These events tend to induce surface wind convergence with moderate magnitude. Through atmospheric reanalysis with high-resolution SST, the present study reveals that, as in the vicinity of the KE, surface wind convergence with moderate magnitude and divergence with moderate-to-extreme magnitude are found to play a primary role in shaping the climatological-mean wind convergence-divergence contrasts across the SST fronts near the Gulf Stream (GS) and Agulhas Return Current (ARC) in winter. In contrast, strong-to-extreme convergence events associated with synoptic-scale atmospheric disturbances are found to yield horizontally uniform time-mean wind convergence. Furthermore, cluster analysis and case studies suggest that persistent atmospheric fronts and SLP troughs are responsible for inducing moderate wind convergence also near the GS and ARC. Thus, these features are consistent with their counterpart near the KE, but the impacts of the ARC tend to be substantially weaker, probably due to its cooler SST among other potential factors.
\end{abstract}

KEYWORDS: Frontogenesis/frontolysis; Boundary currents; Marine boundary layer; Air-sea interaction

¿ Denotes content that is immediately available upon publication as open access.

Corresponding author: Ryusuke Masunaga, ryusukem@hawaii. edu

\section{Introduction}

Satellite and in situ observations have captured local augmentation in time-mean surface wind convergence along the warm midlatitude western boundary currents (WBCs), including the Kuroshio Extension (KE), Gulf 
Stream (GS), and Agulhas Return Current (ARC), and divergence slightly poleward (e.g., Tokinaga et al. 2005; Minobe et al. 2008, 2010; O'Neill et al. 2003, 2005; Nkwinkwa Njouodo et al. 2018). The surface wind convergence accompanies local enhancement in precipitation and cloudiness (e.g., Masunaga et al. 2015; Miyamoto et al. 2018). To adequately represent the wind structure in numerical model experiments and atmospheric reanalysis data, the resolution of prescribed sea surface temperature (SST) data needs to be sufficiently high to resolve mesoscale oceanic features (e.g., Kuwano-Yoshida et al. 2010; Masunaga et al. 2015, 2016, 2018).

The surface wind convergence pattern has been interpreted as a manifestation of local influence of SST distribution with spatial scales of 50-500 km (Small et al. 2008). In this framework, the marine atmospheric boundary layer (MABL) is locally modified by mesoscale SST patterns through surface turbulent heat fluxes. Warm (cool) SST acts to enhance (reduce) upward turbulent heat fluxes, yielding lower (raising) sea level pressure (SLP) and thereby modulating surface wind distribution (Lindzen and Nigam 1987). At the same time, enhanced heat fluxes over warm SST augment downward transport of wind momentum within the MABL by modulating static stability, and thus accelerate surface winds and vice versa (Wallace et al. 1989; Hayes et al. 1989).

Recent studies have, in contrast, suggested significant contributions from synoptic-scale atmospheric disturbances to the time-mean atmospheric fields (e.g., Parfitt and Seo 2018), as the WBC regions are characterized by intense surface baroclinicity sustained by steep gradients in SST and sensible heat flux, and thus core regions of the storm tracks (e.g., Hotta and Nakamura 2011; Nakamura et al. 2004, 2008; Nakamura and Shimpo 2004; Sampe et al. 2010; Ogawa et al. 2012; Parfitt and Czaja 2016). O'Neill et al. (2017) argue that extreme wind convergence and divergence events associated with atmospheric disturbances can leave their signatures on time-mean convergence distribution significantly, and therefore caution needs to be exercised when interpreting mechanisms responsible for shaping the timemean distribution. Parfitt et al. (2016) and Parfitt and Seo (2018) argue that atmospheric fronts can be strengthened when passing across an oceanic front through crossfrontal differential sensible heat fluxes from the ocean, contributing to the enhanced climatological-mean wind convergence in the WBC regions. Furthermore, although time-mean winds are westerlies near the WBCs, air-sea heat exchanges mainly occur under strong cold advection with equatorward winds associated with synoptic-scale disturbances (Nonaka et al. 2009; Taguchi et al. 2009; Miyamoto et al. 2018; Ogawa and Spengler 2019).
Thus, the processes shaping the time-mean frontalscale surface wind convergence pattern are still under debate. Through examining daily-scale evolution of surface winds over the Kuroshio-Oyashio Extension (KOE) region, Masunaga et al. (2020) have shown that atmospheric fronts anchored along the SST front and the frequent generation of meso- $\alpha$ cyclones or SLP troughs play a major role in shaping the time-mean surface wind convergence pattern near the KE in winter. These events induce moderate but persistent surface wind convergence localized along the $\mathrm{KE}$, in which shallow convection and associated latent heating play an important role. In the present study, we apply their methodology to the wintertime GS and ARC regions and discuss their characteristics.

The rest of the present study is organized as follows. The dataset and methods used in the present study are introduced in section 2. In section 3, we discuss spatial distributions of some statistics over the GS and ARC regions. In section 4, we explore specific daily-scale events that yield the time-mean wind convergence pattern through cluster analysis and case studies. We discuss differences in the shaping process between the GS, ARC, and KE regions in section 5. A discussion and summary are given in section 6 .

\section{Data and methods}

\section{a. JRA-55CHS}

As in Masunaga et al. (2020), we use the JRA-55CHS global atmospheric reanalysis product (Masunaga et al. 2018). The horizontal resolution is TL319 (equivalent to approximately $55 \mathrm{~km}$ ) with 60 sigma-pressure hybrid vertical levels. For the lower-boundary condition, the Merged Satellite and In Situ Data Global Daily Sea Surface Temperature (MGDSST) data are prescribed. MGDSST is available with quarter-degree resolution and thus reasonably resolve frontal-scale SST structures in the vicinity of the major WBCs. We use 10-m surface wind components, SLP, and precipitation. Total precipitation is classified into convective and large-scale precipitation. We also use three-dimensional distribution of air temperature, specific humidity, pressure vertical velocity, and diabatic heating rate due to convective processes.

\section{b. Detection of atmospheric fronts}

To objectively detect atmospheric fronts, we use the thermal frontal parameter (TFP) (e.g., Hewson 1998), which is defined as

$$
\mathrm{TFP} \equiv-\nabla|\nabla \tau| \cdot \frac{\nabla \tau}{|\nabla \tau|} .
$$


For a thermal variable $\tau$, we use equivalent potential temperature $\left(\theta_{e}\right)$ estimated through the approximate equations proposed by Bolton (1980). We regard lines of TFP $=0$ with $\left|\nabla \theta_{e}\right| \geq 3 \mathrm{~K}(100 \mathrm{~km})^{-1}$ at 925 -hPa level as atmospheric fronts. For detecting the fronts, we use the JRA-55CHS data rearranged onto $1.25^{\circ}$ grid intervals to avoid noisy and suspicious results.

We can obtain positions of a given atmospheric front on every lattice that the front crosses. The grid point closest to the detected frontal position is regarded as a "frontal grid." We then estimate the horizontal distribution of detection frequency of atmospheric fronts. We also estimate a typical duration of an atmospheric front as a period in which a front is detected successively at a particular grid point on a 6-hourly basis and then locally averaged across all the frontal events. The results shown below are found to be rather insensitive to data resolution, detection methods, and thresholds, as discussed in appendix.

The moving speed of a given atmospheric front perpendicular to the front itself by horizontal advection (hereafter "frontal speed") can be estimated as

$$
\mathbf{v}_{f}=\mathbf{v} \cdot \frac{\nabla T F P}{\mid \nabla T F P},
$$

where $\mathbf{v}$ signifies a horizontal wind vector (e.g., Jenkner et al. 2010), and the atmospheric fronts can be classified into cold and warm fronts, depending on whether $\mathbf{v}_{f}$ is negative or positive, respectively.

For the front detection, the $925-\mathrm{hPa}$ level rather than the surface level is chosen to represent synoptic-scale atmospheric situations. Both $\left|\nabla \theta_{e}\right|$ and wind convergence tend to exhibit vertically coherent structures from the surface up to the $925-\mathrm{hPa}$ level in the vicinity of the oceanic fronts (not shown). It is therefore reasonable to relate the 925 -hPa level diagnostics to the surface wind convergence.

\section{Climatological-mean statistics}

In this section, we investigate climatological statistics for the GS and ARC regions in winter, and compare them with those for the KE region obtained by Masunaga et al. (2020).

\section{a. Fundamental statistics}

Figures $1 \mathrm{~b}$ and $1 \mathrm{f}$ show climatological-mean surface wind convergence for the GS region in January and for the ARC region in July for 1985-2012, respectively. We chose the midwinter months in each hemisphere to highlight typical wintertime characteristics. In both regions, surface wind convergence exhibits distinct maxima on the warmer sides of the SST fronts and divergence maxima slightly poleward, as consistent with satellite observations (e.g., O'Neill et al. 2005; Minobe et al. 2010). Local standard deviation (Figs. 1c,g) and skewness (Figs. 1d,h) are maximized poleward of these wind convergence maxima, implying greater signatures of synoptic-scale atmospheric disturbances on the cooler sides of the SST fronts rather than on the warmer sides.

Total precipitation and ascent in the lower and midtroposphere exhibit prominent maxima coinciding with the surface wind convergence maxima (Fig. 2). In the ARC region, these atmospheric maxima tend to be localized zonally owing to stationary ocean eddies (Liu et al. 2007; Frenger et al. 2013). The maxima in the total precipitation reflect local augmentation of convective precipitation on the warmer sides of the SST fronts (not shown).

The horizontal distributions of these statistics over the GS and ARC regions are thus overall consistent with those over the KE region (Masunaga et al. 2020). Note that the time-mean maxima of these atmospheric fields along the ARC are typically only one-fifth in magnitude of those along the GS and KE, indicative of much weaker influence from the ARC. The weaker impacts of the ARC may be attributable to the cooler SST (Fig. 1e) compared to the GS (Fig. 1a) and KE regions.

\section{b. Frequency and contribution}

Red and blue lines in Fig. 3a show histograms of surface wind convergence on a 6-hourly basis that correspond to the climatological-mean maximum and minimum, respectively, of convergence near the GS as indicated with small boxes in Fig. 1b. These histograms are both characterized by negative mode and strong positive skewness, reflecting substantial contributions from extreme convergence events associated with synoptic-scale disturbances. There are large differences, however, between the red and blue histograms in weak to moderate wind convergence/divergence, while the corresponding differences are smaller in stronger convergence/divergence events.

For a quantitative assessment, a contribution from a given bin to the climatological-mean value is evaluated as the product of the frequency and the mean value for the bin, which can be formulated as

$$
\frac{N_{\text {bin }(i)}}{N_{\text {all }}} \frac{1}{N_{\operatorname{bin}(i)} \operatorname{bin}(i)} \operatorname{CONV}_{\text {bin }(i)}=\frac{1}{N_{\text {all }}} \sum_{\operatorname{bin}(i)} \operatorname{CONV}_{\operatorname{bin}(i)}
$$

Here, $N_{\text {bin(i) }}$ and $N_{\text {all }}$ denote the number of samples in the $i$ th bin and the total number of samples, respectively, 

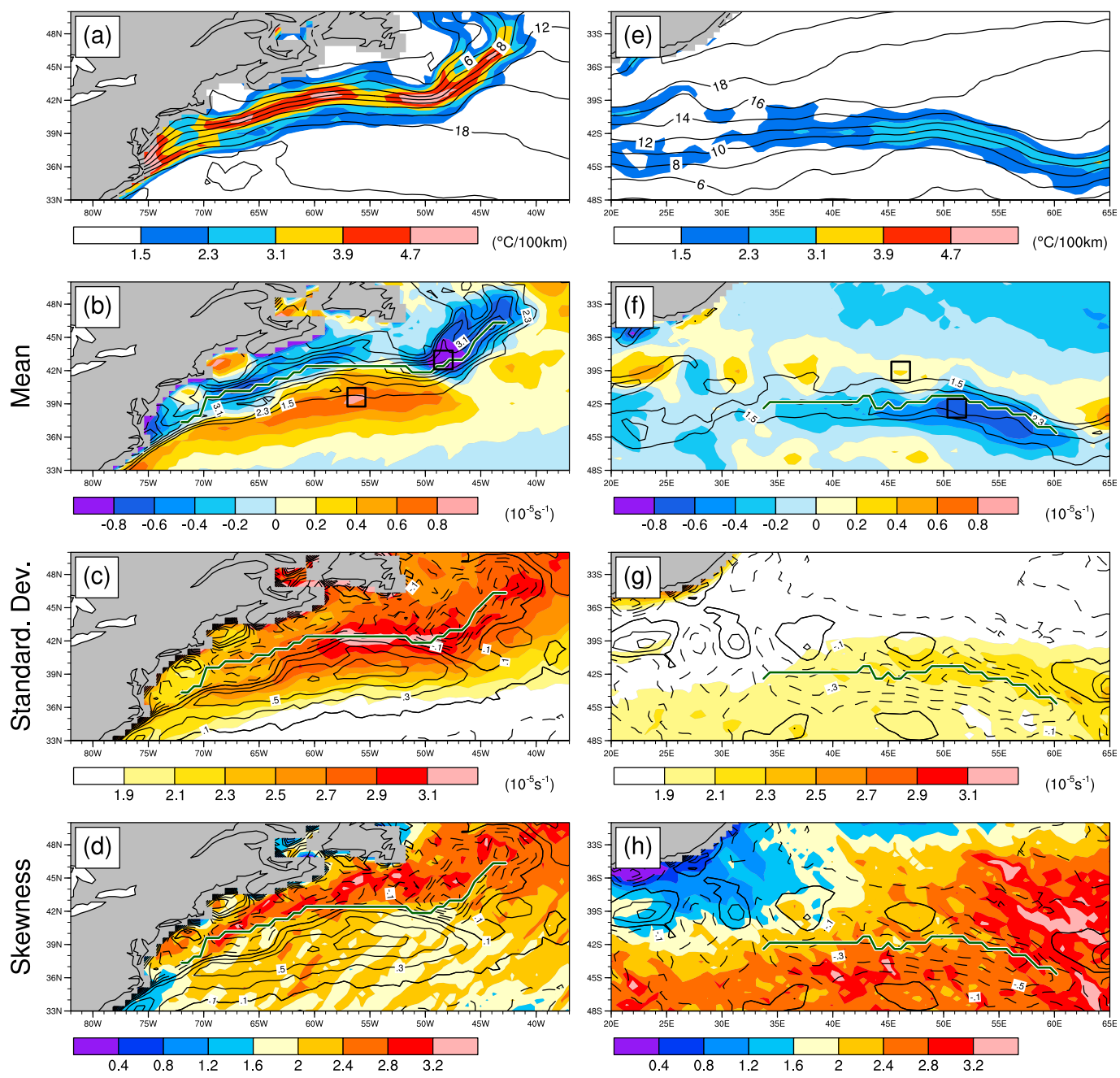

FIG. 1. (a) January climatologies of SST (every $\left.2^{\circ} \mathrm{C}\right)$ and its horizontal gradient [shaded; ${ }^{\circ} \mathrm{C}(100 \mathrm{~km})^{-1}$ ] over the Gulf Stream region for the period 1985-2012 based on JRA-55CHS. (b) As in (a), but for surface wind convergence (shaded; $\left.10^{-5} \mathrm{~s}^{-1}\right)$ and horizontal SST gradient [contoured for every $0.8^{\circ} \mathrm{C}(100 \mathrm{~km})^{-1}$ from $1.5^{\circ} \mathrm{C}$ $\left.(100 \mathrm{~km})^{-1}\right]$. (c) As in (b), but for climatological-mean surface wind convergence (contoured for every $0.2 \times$ $10^{-5} \mathrm{~s}^{-1}$ from $\pm 0.1 \times 10^{-5} \mathrm{~s}^{-1}$ ) and corresponding standard deviation estimated on a 6-hourly basis (shaded; $10^{-5} \mathrm{~s}^{-1}$ ). (d) As in (c), but for skewness (shaded) instead of standard deviation. (e)-(h) As in (a)-(d), but for July over the Agulhas Return Current region. Small boxes in (b) and (f) indicate domains for which histograms in Fig. 3 are estimated. Green lines indicate the axes of SST fronts at which climatological-mean horizontal SST gradients are locally maximized.

and $\mathrm{CONV}_{\text {bin(i) }}$ signifies the set of individual convergence samples falling in the bin. The sum of the contribution from all the bins thus equals the climatological-mean value for the corresponding small box. The differences in contributions between the red and blue lines in Fig. 3b, which signify contributions in shaping the frontal-scale meridional contrast, are distinct around $2 \times 10^{-5}(-3 \times$ $\left.10^{-5}\right) \mathrm{s}^{-1}$ for convergence (divergence) and become smaller for weaker or stronger events. The differences are negligible and even change their sign for wind convergence stronger than $6 \times 10^{-5} \mathrm{~s}^{-1}$.
A role of wind convergence events with a given magnitude can be further clarified quantitatively by accumulating the contribution from negative infinity (Fig. 3c). By definition, a value at the right edge of each line equals to its time-mean wind convergence value. Thus, the contribution from wind convergence events with a given magnitude is proportional to gradients of the accumulation. The gradient of the difference between the red and blue lines, as illustrated with a green line, maximizes at $2.04 \times 10^{-5} \mathrm{~s}^{-1}$ for convergence and $-3.08 \times 10^{-5} \mathrm{~s}^{-1}$ for divergence. To identify wind 

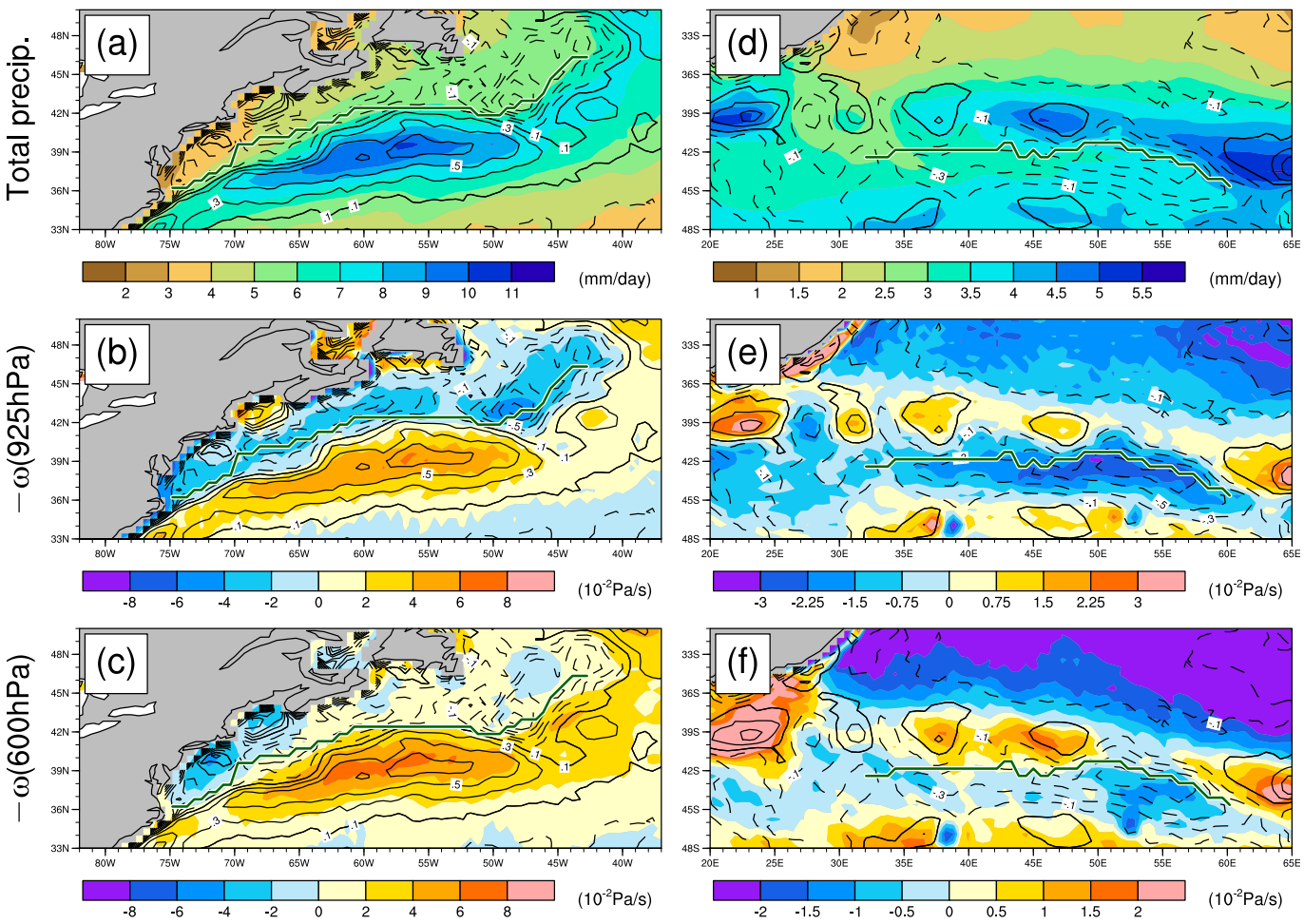

FIG. 2. As in Fig. 1, but for January climatologies over the Gulf Stream region of (a) total precipitation (mm day ${ }^{-1}$; shaded), and vertical velocity as sign-reversed pressure velocity at (b) 925 and (c) $600 \mathrm{hPa}$ $\left(10^{-2} \mathrm{~Pa} \mathrm{~s}^{-1}\right.$; shaded). Contours in (a)-(c) indicate the corresponding climatological-mean surface wind convergence (every $0.2 \times 10^{-5} \mathrm{~s}^{-1}$ from $\pm 0.1 \times 10^{-5} \mathrm{~s}^{-1}$ ). (d)-(f) As in (a)-(c), but for July over the Agulhas Return Current region.

convergence magnitude ranges in which the contribution (the gradient of accumulated contribution) is particularly large, we search wind convergence magnitude ranges in which the contribution exceeds $60 \%$ of the maximum contribution in absolute values. The ranges determined separately for wind convergence and divergence are indicated in Fig. 3 with gray vertical lines and summarized in Table 1 and Table 2 and hereafter referred to as "moderate." The weaker and stronger magnitude ranges are referred to respectively as "weak" and "strong-to-extreme." ${ }^{\text {.1 }}$ As summarized in Table 3, a contribution from a particular magnitude range can then

\footnotetext{
${ }^{1}$ In Masunaga et al. (2020), wind convergence events are categorized rather simply by referring to the percentile values measured over the entire KOE region on a 6-hourly basis, with which moderate wind convergence is defined as $1.21-4.01 \times 10^{-5} \mathrm{~s}^{-1}$. If this criterion is applied to the KOE region, the moderate wind convergence is instead defined as $1.13-4.23 \times 10^{-5} \mathrm{~s}^{-1}$ (Table 1). Nevertheless, we have confirmed that the results shown in Masunaga et al. (2020) are essentially unchanged even if we use the latter magnitude range.
}

be evaluated as the difference between the accumulated contribution values for the larger and smaller thresholds of the magnitude range. For the GS region, the contribution from moderate convergence events is 1.79 times greater than that from strong-to-extreme events, and the contribution from weak convergence events is negligible. Likewise, the contribution from moderate wind divergence events is 2.65 times as large as that from strong-to-extreme divergence events.

The roles of wind convergence/divergence events from the individual categories are further investigated by constructing horizontal maps of their contributions (Fig. 4). The contribution from moderate convergence events exhibits a distinct meridional contrast that well follows the time-mean wind convergence pattern (Fig. 4e). Although the contribution from strong-toextreme convergence events exhibits a zonal band of local maxima (Fig. 4f), it is shifted poleward relative to the time-mean maxima and therefore unlikely to play a primary role in shaping the time-mean wind convergence pattern. On the contrary, the contributions from strong-to-extreme divergent events (Fig. 4a) as well as 
(a) Frequency (\%), Gulf

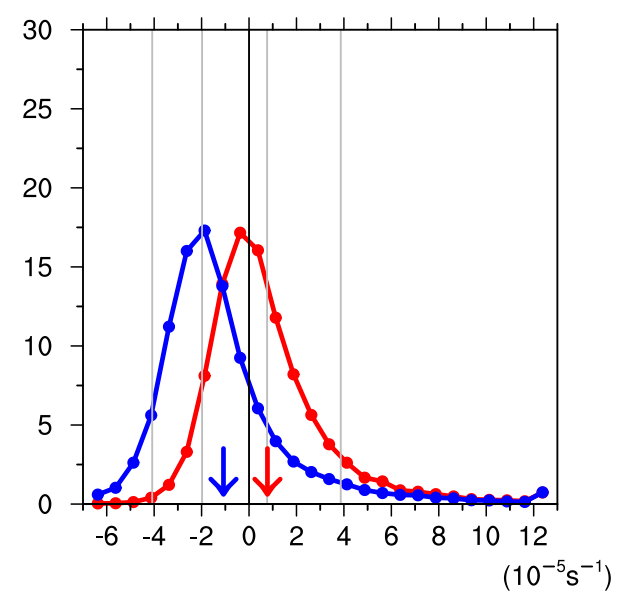

(b) Contribution $\left(10^{-5} \mathrm{~s}^{-1}\right)$, Gulf

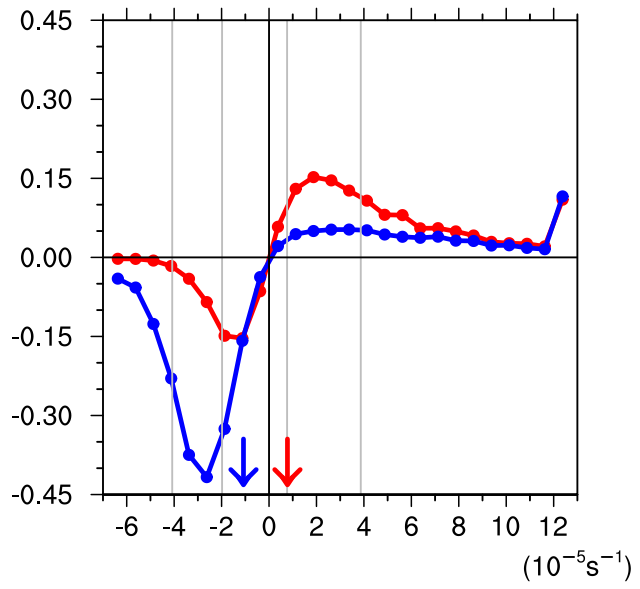

(c) Accumulation $\left(10^{-5} \mathrm{~s}^{-1}\right)$, Gulf

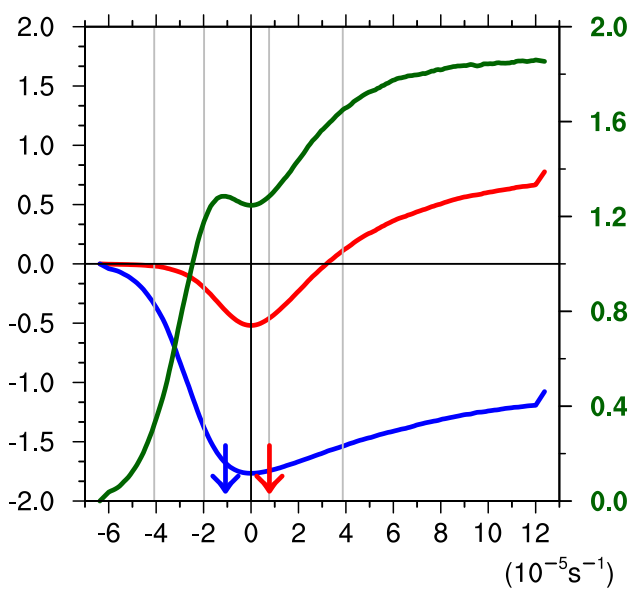

(d) Frequency (\%), Agul.

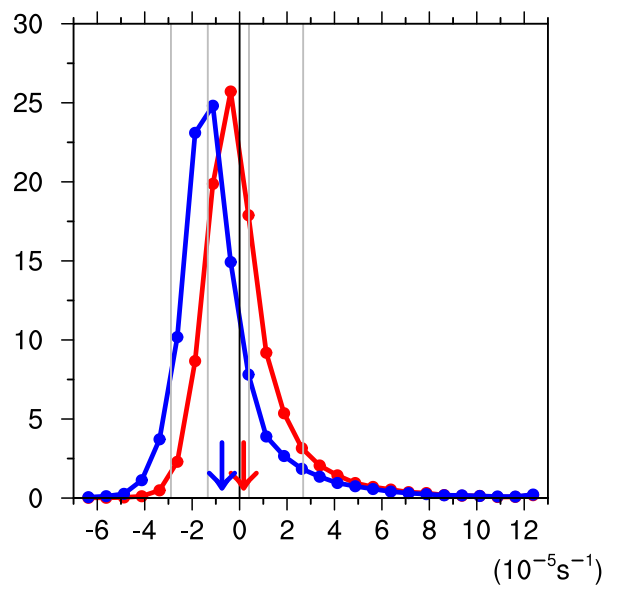

(e) Contribution $\left(10^{-5} \mathrm{~s}^{-1}\right)$, Agul.

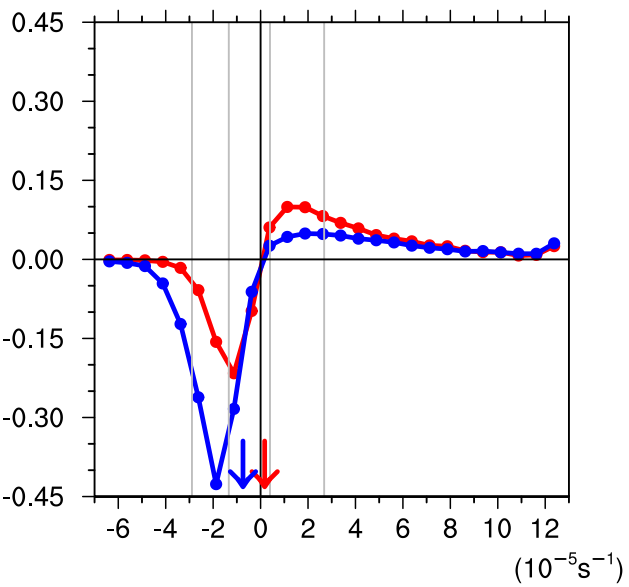

(f) Accumulation $\left(10^{-5} \mathrm{~s}^{-1}\right)$, Agul.

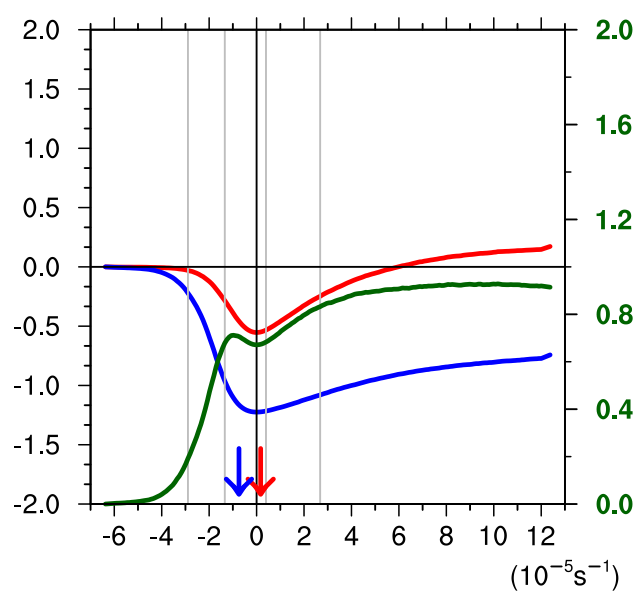

FIG. 3. (a) Histograms of 6-hourly surface wind convergence in January for the period 1985-2012 around the climatological-mean convergence maximum $\left(39.03^{\circ}-40.16^{\circ} \mathrm{N}, 56.75^{\circ}-55.69^{\circ} \mathrm{W}\right)$ (red) and minimum $\left(42.40^{\circ}-\right.$ $43.53^{\circ} \mathrm{N}, 48.94^{\circ}-47.81^{\circ} \mathrm{W}$ ) (blue) near the Gulf Stream as indicated by small boxes in Fig. $1 \mathrm{~b}$. Red and blue arrows indicate the corresponding climatological-mean values of these distributions. Gray vertical lines indicate 
moderate divergence events (Fig. 4b) coincide with the time-mean wind divergence maxima. Weak divergence events also contribute to the time-mean pattern (Fig. 4c), although their contributions are negligible.

As shown in Figs. 3d-f and Tables 1-3, the ARC region exhibits essentially the same features as the GS region. The characteristics of the horizontal distribution of the contributions from individual events for the ARC region (not shown) are also similar to those for the GS region.

Furthermore, we have confirmed that contributions from synoptic-scale disturbances evaluated through the "extreme-value filter" (O'Neill et al. 2017) to the timemean wind convergence field exhibits rather horizontally homogeneous distributions (not shown). Thus, moderate wind convergence events as well as moderateto-extreme wind divergence events are found to play an important role in shaping the time-mean wind convergence pattern near the GS and ARC.

To confirm the robustness of these results, we have repeated the same analysis with regions where climatologicalmean wind convergence is stronger (weaker; i.e., strongly divergent) than $0.6 \times 10^{-5}\left(-0.6 \times 10^{-5}\right) \mathrm{s}^{-1}$ near the GS as "maximum" ("minimum") regions, instead of setting small boxes. We have confirmed that these results described above are essentially unchanged. In the same manner, the robustness has been confirmed for the ARC region by identifying climatological-mean wind convergence with stronger (weaker) than $0.1 \times 10^{-5}\left(-0.1 \times 10^{-5}\right) \mathrm{s}^{-1}$ as maximum (minimum) regions.

These results are consistent with those near the KE as discussed by Masunaga et al. (2020), thus implying that these WBC regions share similar processes to shape the frontal-scale wind convergence pattern in climatology. The similarity is further corroborated by local augmentation in frequency of atmospheric fronts and their duration along the GS and ARC (Fig. 5) as found along the KE. In fact, the absolute frontal speed exhibits local minima along the GS (Fig. 5c). Though not exhibiting a well-defined local minimum, the frontal speed is substantially reduced also on the warm ARC axis than on its colder side (Fig. 5f). These features are essentially the same even if the mean frontal speeds for cold and warm fronts are evaluated separately (not shown).

\section{Cluster analysis and case study}

In this section, we explore typical daily-scale situations where moderate wind convergence is induced near the GS and ARC. First, we chose all events exhibiting surface wind convergence with moderate magnitude at the maxima of climatological-mean wind convergence (i.e., at the center of the small boxes shown in Figs. 1b and 1f). We then classified them into six typical groups by applying the $K$-means clustering for SLP within the rectangular domains indicated in Figs. 6 and 7 to construct their composites. Furthermore, we examine the selected events that typify the composite structures. Masunaga et al. (2020) can be referred to for more detail.

\section{a. Gulf Stream region}

Each of clusters 1-3 is characterized by a weak SLP trough extending along the GS with a well-developed cyclone to the northeast (Fig. 6, C1-C3). The SLP trough accompany surface wind convergence that lasts at least $18 \mathrm{~h}$ (not shown). The background winds are westerlies nearly in parallel to the GS. Upward turbulent heat fluxes and air temperature averaged within MABL are locally augmented along its warm axis (not shown). Thus, the pressure adjustment mechanism (Lindzen and Nigam 1987) can be effectively operative in inducing wind convergence (e.g., Schneider and Qiu 2015). The composited convergence maxima also accompany local maxima in precipitation (Fig. 8, C1-C3).

To further examine the specific events that typify the composite structures, we focus on 6-hourly evolution in January 1993. The monthly-mean wind convergence in January 1993 around the GS (not shown) exhibits the highest spatial correlation (approximately 0.9) with its climatology, and one can therefore expect a typical wintertime daily evolution to be illustrated in this particular month. The composite structures may be typified by an event at 1200 UTC 19 January 1993, which is

threshold values to categorize weak, moderate, and, strong-to-extreme convergence or divergence. (b) As in (a), but for corresponding contributions to the climatological-mean values estimated as the products of frequency and average values of individual bins. (c) As in (b), but integrated from negative infinity to a particular value along the abscissa. The green line signifies their difference (red minus blue; right green ordinate). Note that all of the samples larger (smaller) than $12 \times 10^{-5}\left(-6 \times 10^{-5}\right) \mathrm{s}^{-1}$ are included in the rightmost (leftmost) bin. (d)-(f) As in (a)-(c), but for July near the Agulhas Return Current regions $\left(39.59^{\circ}-38.47^{\circ} \mathrm{S}, 45.56^{\circ}-46.69^{\circ} \mathrm{E}\right.$, red lines; and $42.96^{\circ}-41.84^{\circ} \mathrm{S}, 50.63^{\circ}-51.75^{\circ} \mathrm{E}$, blue lines). 
TABLE 1. Wind convergence magnitude $\left(\times 10^{-5} \mathrm{~s}^{-1}\right)$ for which the gradients in the accumulated contribution differences (green lines in Fig. 3) are maximized. The magnitude ranges where the gradients exceed $60 \%$ of the maxima are indicated as well, which are referred to as "moderate" in the present study. The corresponding percentiles measured for the red and blue histograms combined in Figs. 3a or 3d are indicated in parentheses. The corresponding values obtained for the small boxes over the KOE region shown in Masunaga et al. (2020) are also indicated for reference.

\begin{tabular}{lcc}
\hline \hline \multicolumn{1}{c}{ Region } & Contribution maximum & "Moderate" magnitude range \\
\hline Gulf Stream & $2.04(84 \mathrm{th})$ & $0.76(72 \mathrm{nd})$ to 3.87 (92nd) \\
Agulhas Return Current & $0.94(83 \mathrm{rd})$ & $0.4(76 \mathrm{th})$ to $2.68(93 \mathrm{rd})$ \\
Kuroshio Extension & $2.59(88 \mathrm{th})$ & $1.13(75 \mathrm{th})$ to 4.23 (94th) \\
\hline
\end{tabular}

classified into cluster 1 (Fig. 9). As passing through the domain, an atmospheric front seems to be anchored along the GS, accompanying convergence (top panels), precipitation (bottom panels), and ascent at $925 \mathrm{hPa}$ (not shown) and $600 \mathrm{hPa}$ (middle panels). These distributions resemble their climatologies (Fig. 2). Daily events classified into any of clusters 1-3 are found to illustrate similar features. Furthermore, the number of the snapshots is counted in which atmospheric fronts are identified near the target point $\left(38.125^{\circ}-43.125^{\circ} \mathrm{N}\right.$, $56.875^{\circ}-55.625^{\circ} \mathrm{W}$ ) for each of the clusters (Fig. 10a). For clusters 1 (black) and 2 (cyan), as much as $\sim 80 \%$ of the snapshots accompany atmospheric fronts at lag 0 and the percentage remains high for the next $18 \mathrm{~h}$. For cluster 3 (blue), the percentage increases up to $\sim 72 \%$ toward the lag of $12 \mathrm{~h}$, which is likely to reflect the transition from the cluster 3 distribution to clusters 1 or 2. These results indicate that the persistent wind convergence tends to accompany atmospheric fronts, and the results are found to be rather insensitive to the choice of regions to search atmospheric fronts.

The cluster 5 composite (Fig. 6, C5) features a SLP trough, which accompanies maxima in precipitation (Fig. 8, C5) and surface heat fluxes, extending eastward along the GS toward an anticyclonic center. This situation may be typified by an event at 0000 UTC 8 January 1993 (Fig. 11), where a SLP trough was developing eastward along the GS toward an anticyclonic center. The SLP trough persisted for more than a day, accompanying ascent and precipitation.

The cluster 4 composite is characterized by a meridionally oriented SLP trough north of the GS within the western portion of the domain (Fig. 6, C4). Examination of daily events suggests that this SLP trough is mostly a manifestation of a major cold front extending from a cyclone center to the north, although the signature has been smeared by the compositing. Likewise, the cluster 6 composite features passage of a synoptic-scale cyclone (Fig. 6, C6). Nevertheless, nearly $70 \%$ of the total snapshots belong to clusters 1-3 and 5, where no synoptic-scale disturbances are identified in the vicinity of the GS.

\section{b. Agulhas Return Current region}

As in the GS regions, each of clusters 1-3 for the ARC region (Fig. 7, C1-C3) is characterized by a welldeveloped cyclone poleward of a local maximum of moderate wind convergence along the SST front associated with the ARC. Precipitation (Fig. 12, C1-C3) and upward surface heat fluxes (not shown) are also locally augmented around the convergence maximum. These distributions suggest that anchoring of atmospheric fronts along the SST front may occur as along the GS. Compared to the corresponding clusters 1-3 for the GS region, however, we found it rather difficult to identify persistent wind convergence events that seem to be sustained by the SST front just by inspecting daily scale evolution visually. Indeed, Fig. 10b shows that the percentage of atmospheric fronts identified near the target point is lower and less persistent than those near the GS (note that ordinates are different between the two panels). Still, the maximum fraction reaches $\sim 60 \%$ for clusters 1 (black) and 2 (cyan) around lag 0 , and lag $12 \mathrm{~h}$ for cluster 3 (blue). In fact, anchoring of an atmospheric

TABLE 2. As in Table 1, but for divergence.

\begin{tabular}{lcc}
\hline \hline \multicolumn{1}{c}{ Region } & Contribution maximum & "Moderate" magnitude range \\
\hline Gulf Stream & $-3.08(11$ th $)$ & $-4.08(4$ th $)$ to $-2.00(25$ th $)$ \\
Agulhas Return Current & $-1.98(14$ th $)$ & $-2.89(4$ th $)$ to $-1.34(30$ th $)$ \\
Kuroshio Extension & $-2.53(10$ th $)$ & $-3.35(3 \mathrm{rd})$ to $-1.61(25$ th $)$ \\
\hline
\end{tabular}


TABLE 3. Contributions from weak, moderate, and strong-to-extreme events of surface wind convergence or divergence $\left(\times 10^{-5} \mathrm{~s}^{-1}\right)$, corresponding to the green lines in Figs. 3c and 3f. Each of the contributions is evaluated as the difference between accumulated contribution values at the larger and smaller thresholds of a given magnitude category. The bottom two rows indicate the ratios of the contributions from moderate events to those from strong-to-extreme events. The corresponding values obtained for the small boxes over the KOE region shown in Masunaga et al. (2020) are also indicated for reference.

\begin{tabular}{lccc}
\hline \hline \multicolumn{1}{c}{ Category } & $\begin{array}{c}\text { Gulf } \\
\text { Stream }\end{array}$ & $\begin{array}{c}\text { Agulhas Return } \\
\text { Current }\end{array}$ & $\begin{array}{c}\text { Kuroshio } \\
\text { Extension }\end{array}$ \\
\hline Weak convergence & 0.04 & 0.01 & 0.05 \\
Moderate convergence & 0.37 & 0.15 & 0.42 \\
Strong-to-extreme convergence & 0.20 & -0.01 & 0.10 \\
Weak divergence & 0.07 & 0.49 & 0.08 \\
Moderate divergence & 0.86 & 0.19 & 0.48 \\
Strong-to-extreme divergence & 0.32 & 1.82 & 0.16 \\
Ratio (moderate convergence/strong-to- & 1.79 & & 4.04 \\
$\quad$ extreme convergence) & & 2.54 & 2.94 \\
Ratio (moderate divergence/strong-to- & 2.65 & & \\
$\quad$ extreme divergence) & & & \\
\hline
\end{tabular}

front near the ARC is hinted at in an event at 1800 UTC 8 July 1994 (Fig. 13), which is classified into cluster 1. The atmospheric front extended in the northwestsoutheast orientation east of $50^{\circ} \mathrm{E}$, whereas it extended zonally to the west to better follow the ARC accompanied by zonally oriented bands of precipitation and ascent.

The cluster 4 composite features a SLP trough in the western portion of the domain behind a pressure ridge (Fig. 7, C4). Examination of daily events suggests that this cluster mostly illustrates passage of synoptic-scale cyclones in the proximity of the target point (not shown), as in cluster 4 of the GS. Meanwhile, clusters 5 and 6 are characterized by surface westerlies poleward of prominent anticyclones (Fig. 7, C5 and C6). The associated wind convergence maxima coincide with marked maxima in meridionally high-pass-filtered precipitation (not shown), as hinted in their raw distributions (Fig. 12, C5 and C6). Although influence of the SST front on the daily wind convergence is also rather
Conv. $<-4.1$
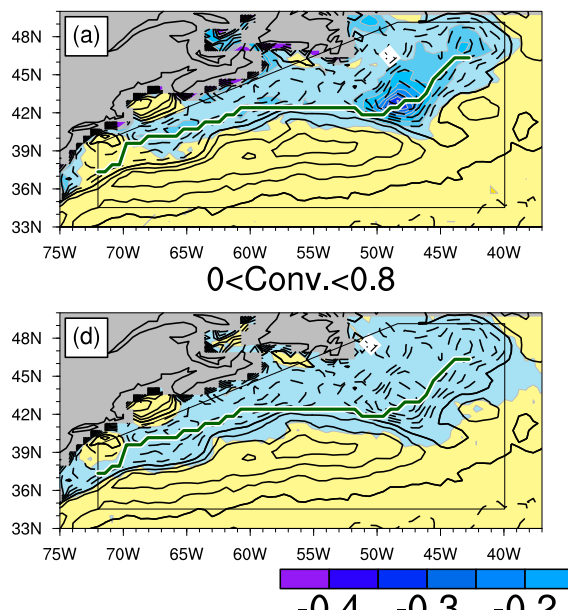

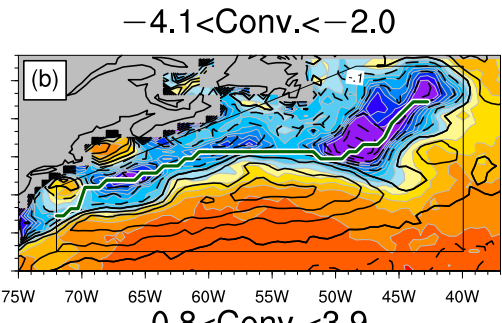

$0.8<$ Conv. $<3.9$

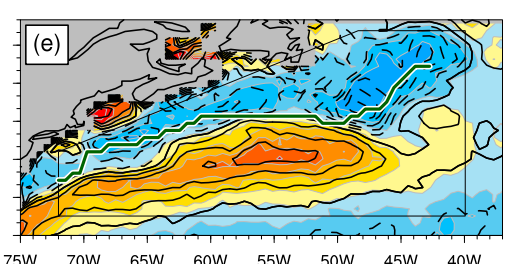

$75 \mathrm{~W} \quad 70 \mathrm{~W} 65 \mathrm{~W}$ 60W $55 \mathrm{~W}$ 50W $45 \mathrm{~W} \quad 40 \mathrm{~W}$
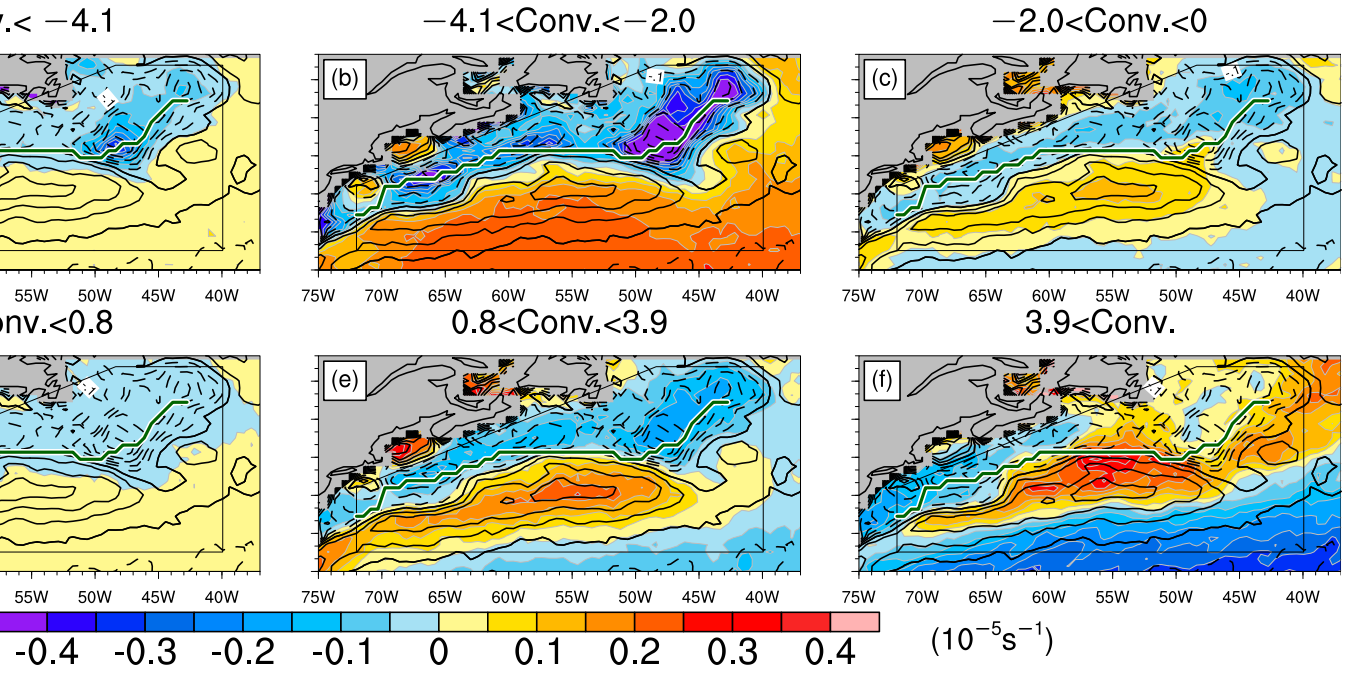

FIG. 4. Contributions $\left(10^{-5} \mathrm{~s}^{-1}\right.$; shaded as indicated at the bottom) of 6-hourly surface wind convergence events in January with magnitude indicated above each panel (negative for divergence) evaluated for the period 1985-2012 based on JRA-55CHS. Corresponding climatology is superimposed with black contours $\left(10^{-5} \mathrm{~s}^{-1}\right.$; indicated for $\pm 0.1, \pm 0.3, \pm 0.5 \times 10^{-5} \mathrm{~s}^{-1}, \ldots$; negative for divergence). The area average over the Gulf Stream region indicated with thin black lines has been subtracted from each of the contribution distributions. Green lines indicate the axis of the SST front at which climatological-mean horizontal SST gradients are locally maximized. 
(a) Gulf, Frequency, Jan., 925hPa

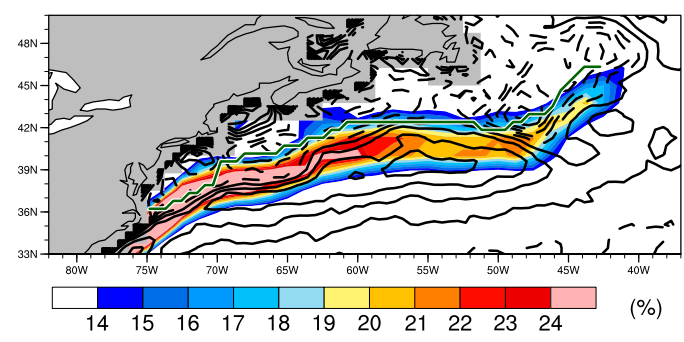

(b) Gulf, Duration, Jan., $925 \mathrm{hPa}$

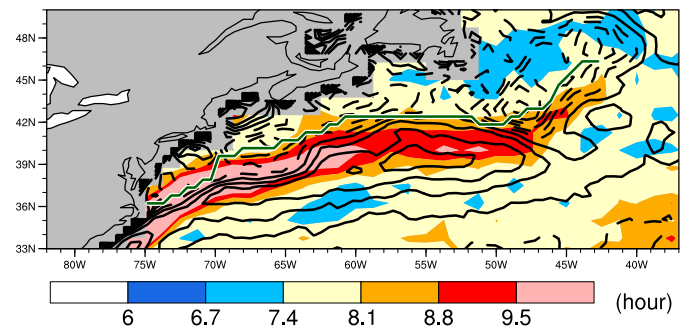

(c) Gulf, Speed, Jan., $925 \mathrm{hPa}$

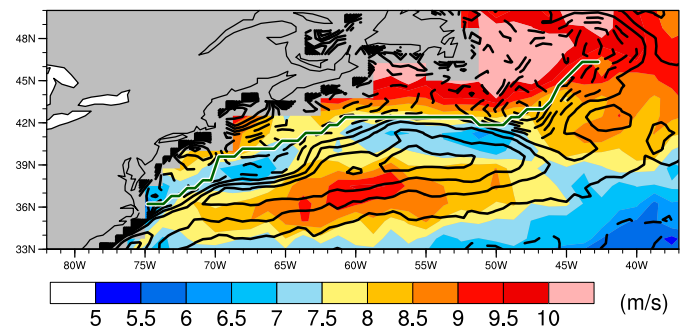

(d) Agulhas, Frequency, Jul., $925 \mathrm{hPa}$

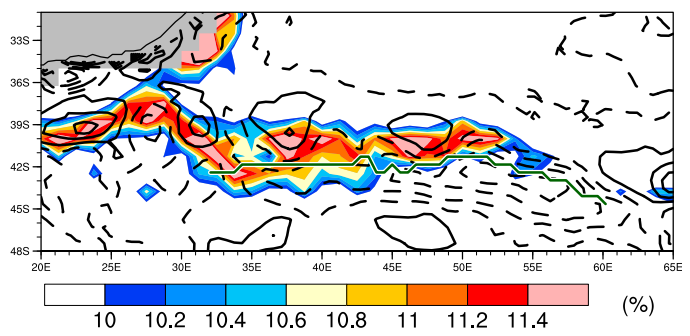

(e) Agulhas, Duration, Jul., $925 \mathrm{hPa}$

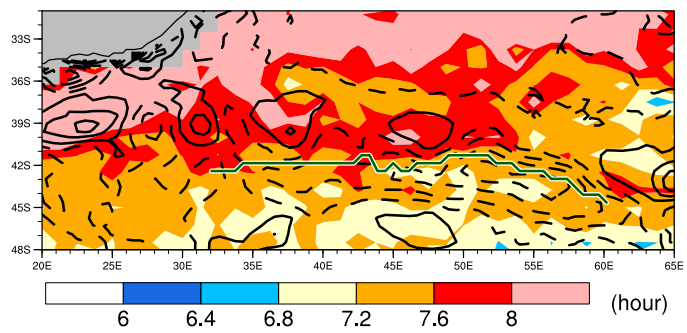

(f) Agulhas, Speed, Jul., $925 \mathrm{hPa}$

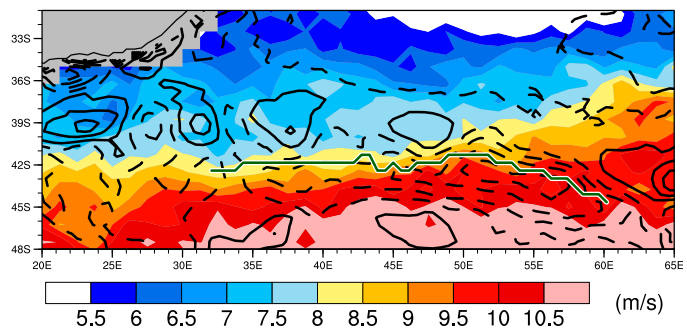

FIG. 5. As in Fig. 2, but for (a) detection frequency (\%; shaded) and (b) mean duration (h; shaded) of atmospheric fronts at the 95-hPa level, and (c) corresponding absolute frontal speeds [i.e., $\mathbf{v}_{f}$ in Eq. (2)] ( $\mathrm{m} \mathrm{s}^{-1}$; shaded) for the frontal grids in January over the Gulf Stream region. (d)-(f) As in (a)-(c), respectively, but in July over the Agulhas Return Current region.

unclear in these clusters, we can identify an event at 0600 UTC 15 July in 2006 (Fig. 14), which is typical for cluster 5 . The event is characterized by an atmospheric front formed along the prominent SST front on the poleward fringe of an anticyclone. The atmospheric front accompanied zonal bands of surface wind convergence, precipitation, and $700-\mathrm{hPa}$ ascent (not shown), while the ascent did not reach the $600-\mathrm{hPa}$ level.

\section{Comparison between the GS, ARC, and KE regions}

The results in the preceding sections suggest that the GS region shares the same shaping processes with the $\mathrm{KE}$ region as discussed by Masunaga et al. (2020). There are, however, some differences worth pointing out. In the KE region, generation of meso- $\alpha$ cyclones over the $\mathrm{KE}$ is identified as one of the dominant processes, as illustrated by cluster 4 in the KOE region (Masunaga et al. 2020), whereas it is less dominant in the GS region. That is probably because, near the KE, Honshu Island (Japan) acts to induce wind convergence topographically off the Boso Peninsula under the northwesterlies (e.g., Kawase et al. 2006), frequently triggering meso$\alpha$ cyclogenesis. In contrast, the target point set for the GS region in the present study is relatively far away from the North American continent so that GS influence seems to be mostly responsible for yielding the mesoscale atmospheric features. The situation, however, may differ in the western portion of the GS just off Cape Hatteras, where atmospheric fronts are detected more frequently (Fig. 5).

Over the ARC domain, formation of surface wind convergence along the SST front under anticyclones (as in clusters 5 and 6 in Fig. 7) is found to be more frequent than over the GS region. In this situation, the background westerlies tend to be rather weak and nearly in 
$\mathrm{N}=213(20.6 \%)$

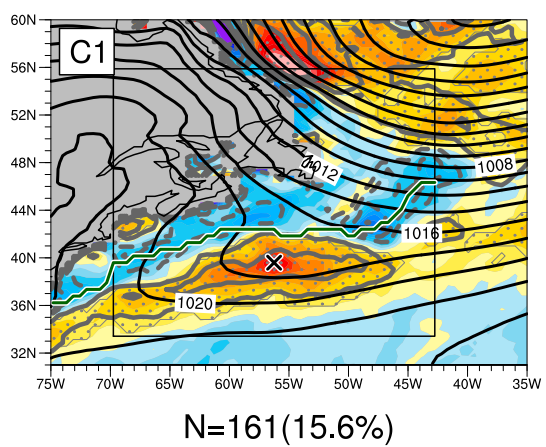

$\mathrm{N}=161(15.6 \%)$

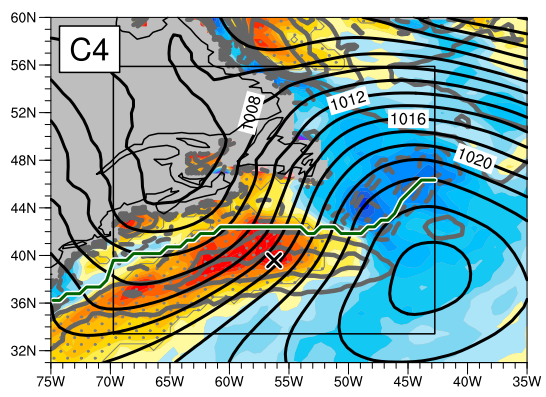

$\mathrm{N}=208(20.2 \%)$

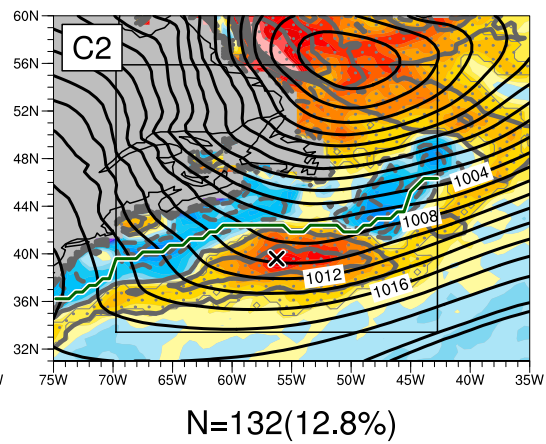

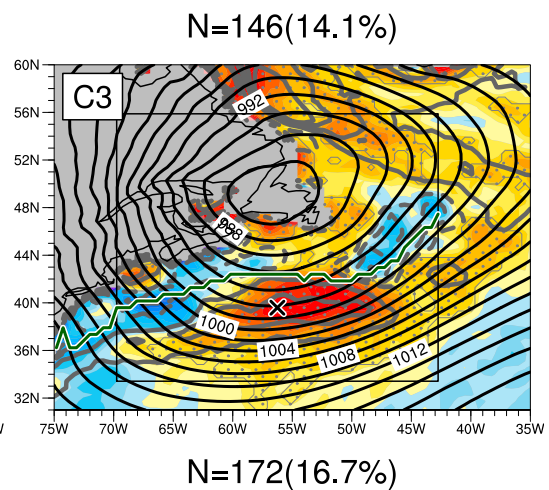

$\mathrm{N}=172(16.7 \%)$

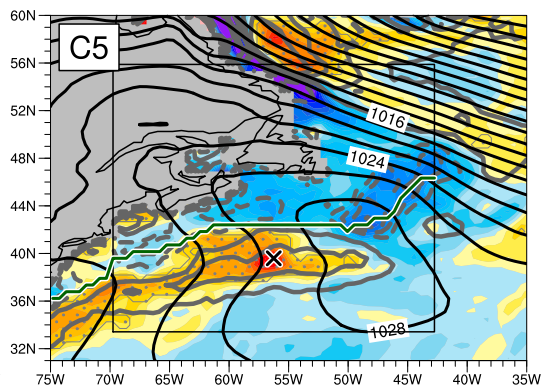

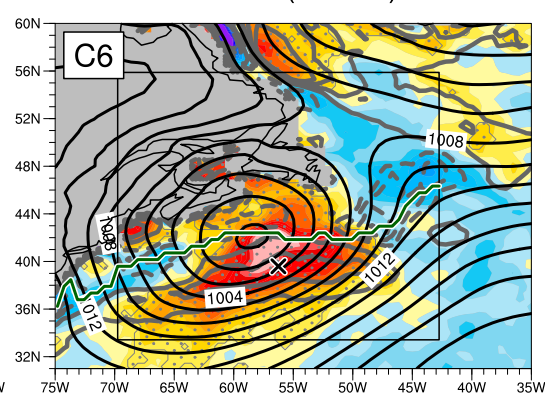

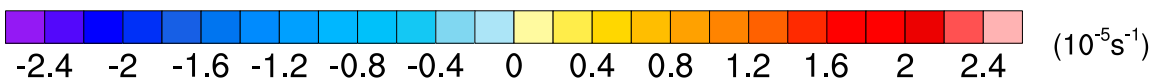

FIG. 6. Composites of surface wind convergence in January (shaded as indicated at the bottom) and SLP (contoured every $2 \mathrm{hPa}$ ) constructed with time steps that exhibit surface wind convergence of $0.76-3.87 \times 10^{-5} \mathrm{~s}^{-1}$ at $39.59^{\circ} \mathrm{N}, 56.25^{\circ} \mathrm{W}$ (cross marks) based on JRA-55CHS for the period 1985-2012. These events (1032 samples in total) are classified into six clusters (labeled as C1-C6) by applying the $K$-means clustering method for SLP within the boxes indicated with thin black lines. Hatching is applied where the composited surface wind convergence is locally significant at the $98 \%$ confidence level estimated by one-sided bootstrap test with repeating bootstrap sampling 1000 times. Thick gray contours indicate the corresponding climatology of surface wind convergence (every $0.3 \times 10^{-5} \mathrm{~s}^{-1}$; zero contours are omitted). Green lines indicate the axes of SST fronts, at which composited SST gradients are locally maximized.

parallel with the SST front, which are favorable for the pressure adjustment mechanism (e.g., Kilpatrick et al. 2016; Schneider and Qiu 2015). Although the results above suggest that the anchoring of atmospheric fronts can occur also along the ARC, influence from the SST front on daily-scale events seems to be substantially weaker, as inferred from the weaker climatologicalmean wind convergence (Fig. 1). Indeed, detection frequency of atmospheric fronts along the ARC is smaller and their duration is shorter (Fig. 5).

Masunaga et al. (2020) have suggested that persistent shallow convections can be responsible for the anchoring of atmospheric fronts along SST fronts and for the warming of MABL, both of which lead to persistent wind convergence. Thus, the weaker imprints of the ARC are consistent with the weaker convective heating than along the GS in climatology (Fig. 15) and cluster composites (not shown), despite local maxima along the ARC. The weaker convective heating is probably due to the cooler SST near the ARC (typically by $2^{\circ} \mathrm{C}$ ). Minobe et al. (2010), for example, argued that atmospheric convection near the GS is weaker in winter than in summer because of the seasonally cooler SST. They also speculated that convection in the ARC region would be weak throughout the year because of cooler SST. Indeed, the turbulent heat fluxes composited for the individual clusters tend to be substantially greater over the GS than over the ARC (not shown). Likewise, the horizontal gradients in the composited heat fluxes are more than $60 \%$ stronger along the GS front, as consistent with the steeper SST gradients, and thus the "thermal damping and strengthening" mechanism (Parfitt and Seo 2018) can be more effective.

Kuwano-Yoshida et al. (2010) argued that atmospheric convection tends to be persistent along the warm GS, where high convective available potential energy (CAPE) is sustained during convection events. In fact, CAPE along the GS (Fig. 15c) is climatologically higher 
$\mathrm{N}=143(17.1 \%)$
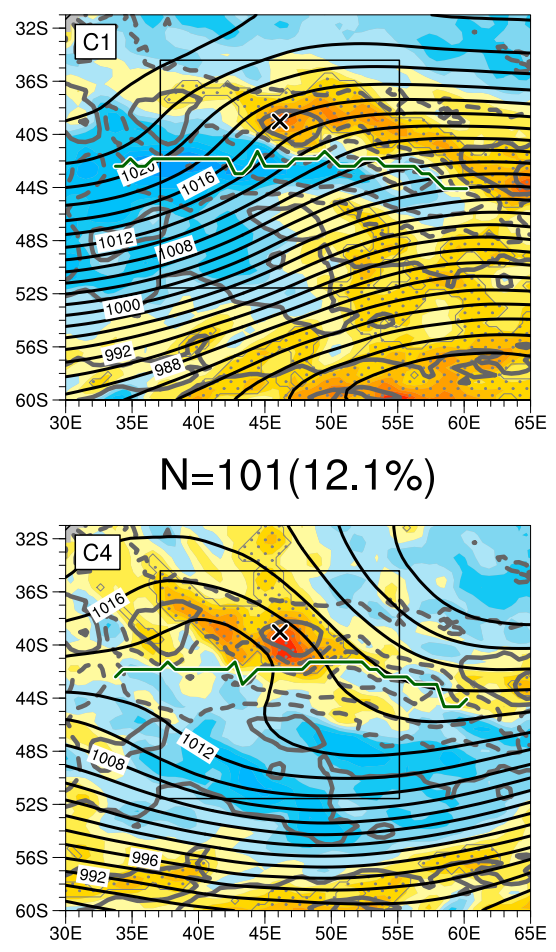

$\mathrm{N}=108(12.9 \%)$

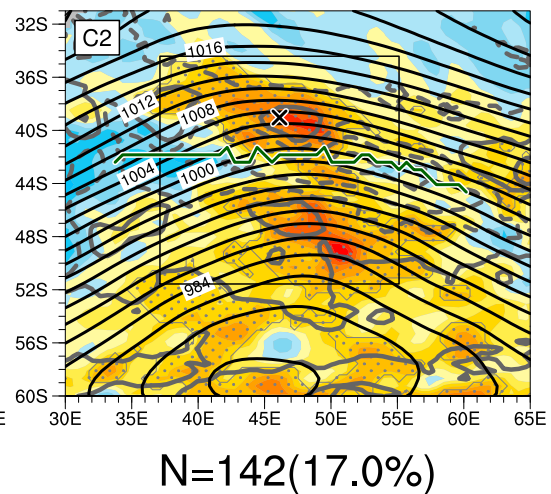

$\mathrm{N}=179(21.4 \%)$

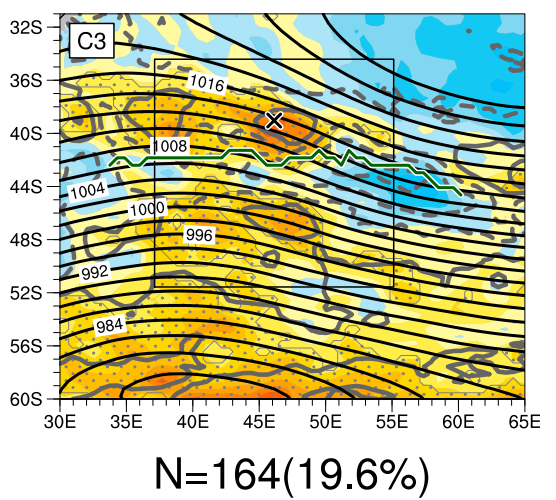

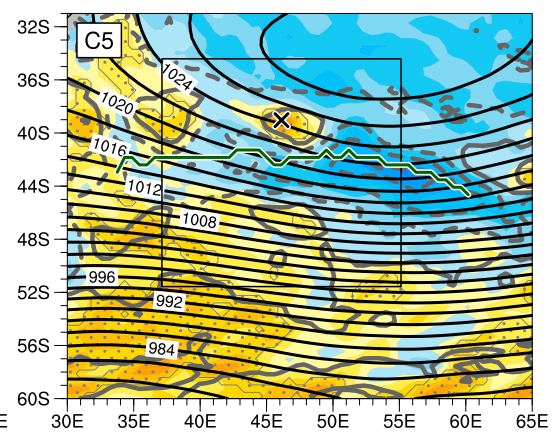

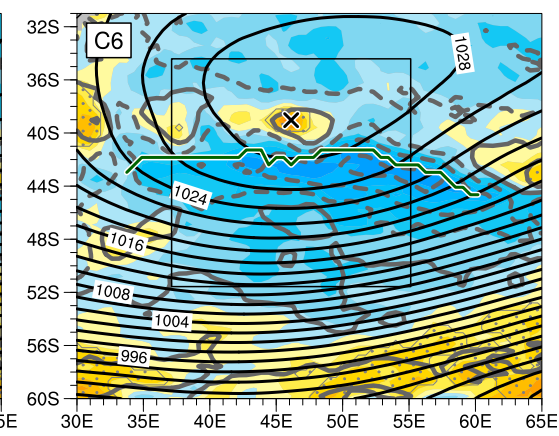

FIG. 7. As in Fig. 6, but constructed for the Agulhas Return Current region in July with time steps that exhibit surface wind convergence of $0.40-2.68 \times 10^{-5} \mathrm{~s}^{-1}$ at $39.03^{\circ} \mathrm{S}, 46.13^{\circ} \mathrm{E}$ indicated by cross marks (837 samples in total). Corresponding climatological-mean wind convergence is superposed with thick gray contours $\left(10^{-5} \mathrm{~s}^{-1}\right.$; indicated for $\pm 0.1, \pm 0.4, \pm 0.7 \times 10^{-5} \mathrm{~s}^{-1}, \ldots$; negative for divergence).

than along the ARC (Fig. 15d), which is indicative of higher potential to induce active convection and thus in agreement with greater convective heating.

To further elucidate the role of CAPE, time evolutions of CAPE for the individual clusters are shown in Fig. 16 after averaged over the rectangular domains encompassing the target points shown in Fig. 15. The results are found to be insensitive to the domain size. As shown in Fig. 16a, CAPE tends to be kept around $110 \mathrm{~J} \mathrm{~kg}^{-1}$ or higher throughout the events in clusters 1 (black) and 2 (cyan) for the GS region. In the same manner, CAPE tends to increase to the level of $110 \mathrm{~J} \mathrm{~kg}^{-1}$ in cluster 5 (green) for the GS region. These are the same characteristics as found in a numerical experiment by Kuwano-Yoshida et al. (2010). By contrast, CAPE remains rather low or declines in clusters 1 , 4, 5 , and 6 for the ARC region (Fig. 16b). Thus, it would be worth investigating CAPE in detail as one of the important factors in future study. However, CAPE cannot fully explain the differences between the WBC regions. For example, CAPE is kept relatively high in clusters 2 and 3 for the ARC region, but convection tends to be less persistent. Furthermore, the CAPE evolution appears to simply reflect the influence of synoptic-scale disturbances passing near the target domain, rather than local imprints of the GS, in clusters 3 , 4 , and 6 for the GS region. Thus, more elaborate investigation is needed to fully elucidate the differences in the imprints of the WBCs on atmospheric convective activity.

Another important feature is that synoptic-scale cyclones are less frequent along the ARC, as shown in a cyclone density map by Neu et al. (2013). This is consistent with our finding of less frequent atmospheric fronts (Fig. 5) and our cluster composites (Fig. 7), none of which illustrates any clear cyclone signature as in cluster 6 for the GS region. In addition to the weaker influence from the ARC, the less frequent atmospheric fronts may act to prevent persistent atmospheric fronts from forming in the ARC region and thereby lead to weaker time-mean wind convergence-divergence contrast across the SST front along the ARC. The less 

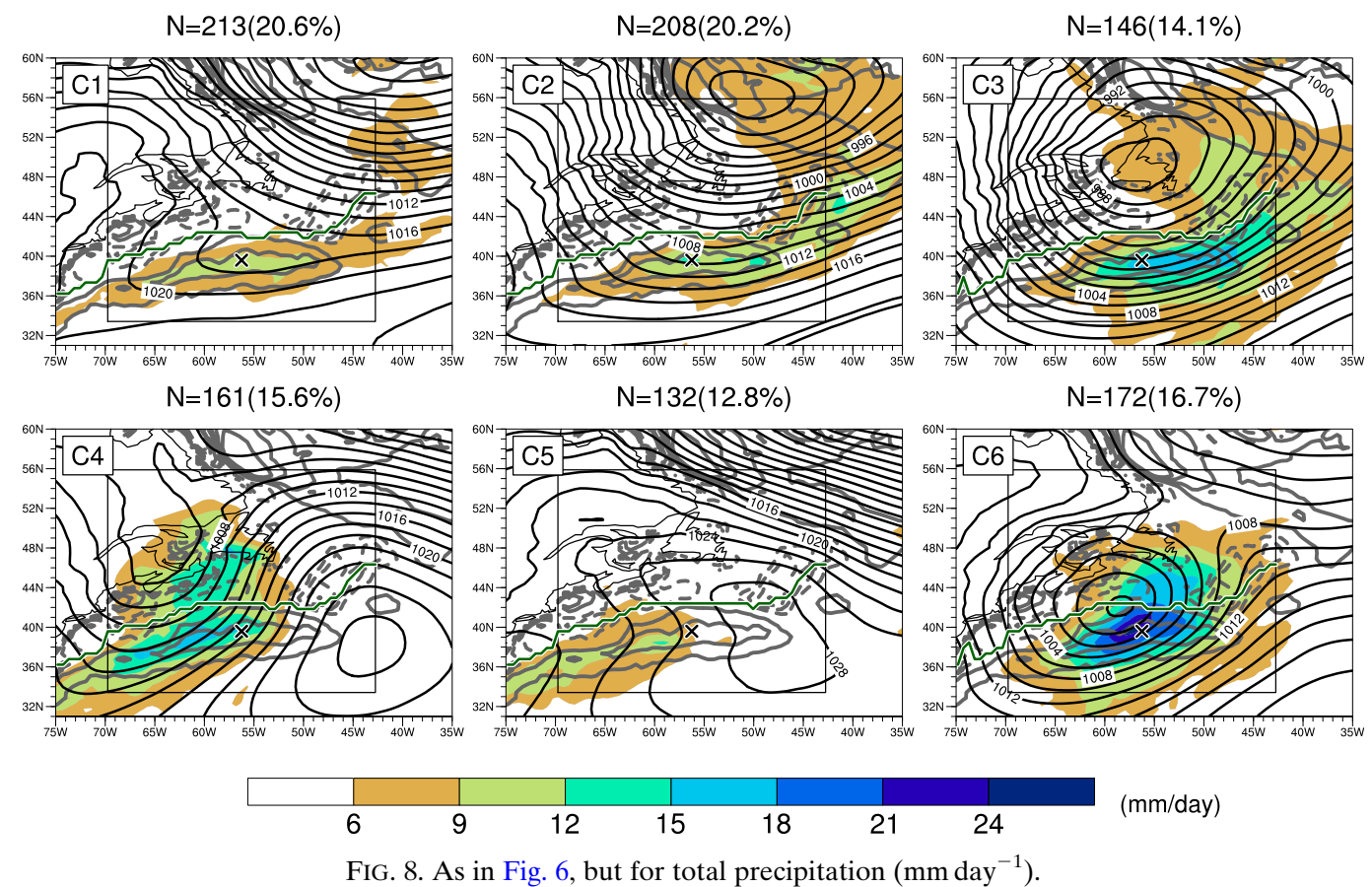

frequent extreme events may also contribute to the weaker time-mean wind convergence (O'Neill et al. 2017).

\section{Discussion and summary}

In the present study, daily-scale processes that are responsible for shaping the time-mean frontal-scale surface wind convergence patterns near the GS and ARC in winter have been explored by adopting the methodology used by Masunaga et al. (2020). By examining their frequency and corresponding contributions to the climatological-mean values, daily scale surface wind convergence with moderate strength and divergence with moderate-to-extreme strength are found to play a primary role. The signature of strong-to-extreme

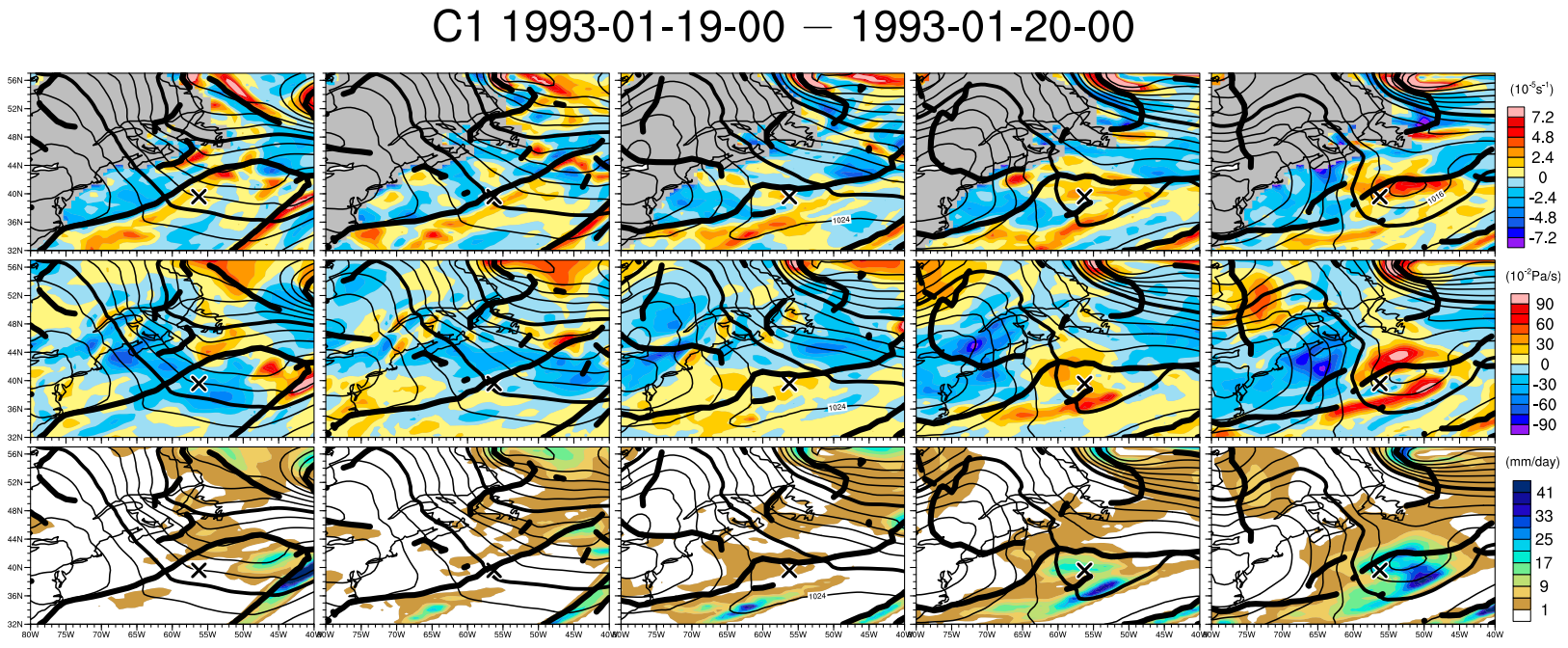

FIG. 9. Snapshots of 6-hourly SLP (contoured for every $4 \mathrm{hPa}$; thickened for 1000 and $1020 \mathrm{hPa}$ ) superimposed on (top) surface wind convergence (shaded as indicated to the right), (middle) vertical velocity as sign-reversed pressure vertical velocity at $600 \mathrm{hPa}$ (shaded), and (bottom) total precipitation (shaded) for the 24-h period from 0000 UTC 19 Jan 1993. Thick black lines indicate atmospheric fronts at the 925-hPa level. The cross marks are as in Fig. 6. 

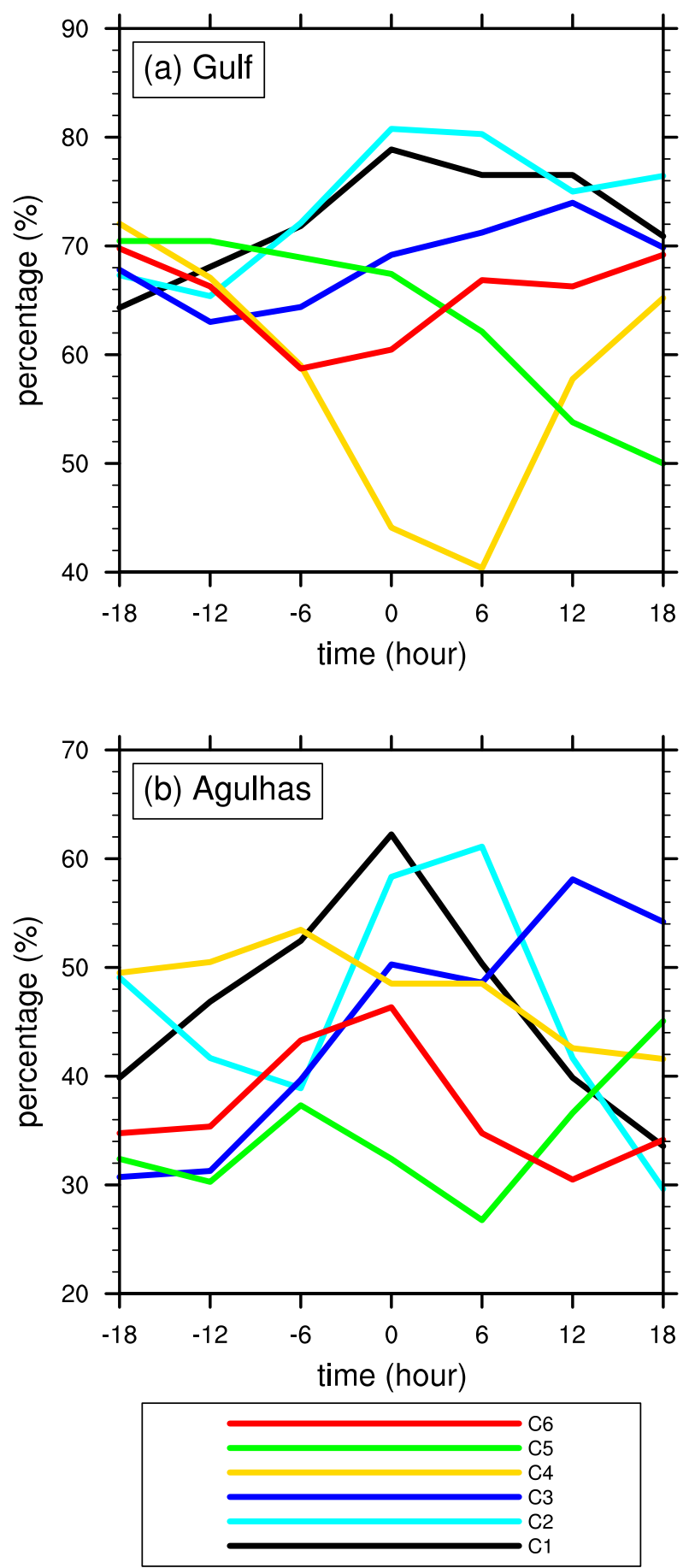

FIG. 10. Percentage of snapshots for each cluster (as line convention shown in the plot) in which atmospheric fronts are identified within each of the rectangular domains encompassing the target point in the (a) GS region $\left(38.125^{\circ}-43.125^{\circ} \mathrm{N}, 56.875^{\circ}-\right.$ $\left.55.625^{\circ} \mathrm{W}\right)$ and $(\mathrm{b})$ ARC region $\left(43.125^{\circ}-38.125^{\circ} \mathrm{S}, 45.625^{\circ}-46.875^{\circ} \mathrm{E}\right)$. The abscissa signifies time lags relative to each snapshot used for constructing a given cluster in Figs. 6 and 7 for (a) and (b), respectively. convergence events is, however, found to yield a horizontally uniform contribution.

We have further explored typical daily events that induce moderate wind convergence along the WBCs. Our cluster analysis and case studies suggest that atmospheric fronts that are persistent along the SST fronts and formation of SLP troughs can play an important role in shaping the time-mean convergence pattern near the GS. These processes tend to induce moderate but persistent surface wind convergence localized along the GS, accompanying bands of precipitation maxima and ascent. These features are consistent with those near the KE. Although similar events can be identified also along the ARC, the signatures tend to be substantially weaker.

We argue that the vertical mixing mechanism, another hypothesis by which ocean fronts can affect the overlying atmosphere (Wallace et al. 1989), is mainly responsible for yielding wind divergence on the SST fronts. As in the $\mathrm{KOE}$ region, persistent wind divergence with moderate amplitude coincides well with the SST fronts in the GS and ARC regions (not shown), suggestive of operative vertical mixing mechanism. Intensive investigation for elucidating the mechanisms is left for our future work.

Parfitt and Seo (2018) suggested, using the so-called $F$ diagnostic, that atmospheric fronts play an important role in shaping the time-mean surface wind convergence. While they did not refer to the strength and persistence of atmospheric fronts, we have confirmed that their $F$ diagnostic can capture atmospheric fronts that become persistent neat the GS. Given that their method identifies atmospheric fronts more frequently $(\sim 25 \%)$ along the GS than the present study $(\sim 22 \%)$, their frontal average is likely to include a contribution from weak and persistent atmospheric fronts with moderate surface wind convergence, in addition to a contribution from extreme convergence. Furthermore, since the $F$ diagnostic uses both vorticity and temperature gradients, the SLP trough structure (Fig. 6, C5) can also be included in their frontal average. Our results thus do not contradict Parfitt and Seo (2018), but we present more detailed perspective through cluster analysis and case studies.

We leave for our future work the investigation of specific mechanisms through which atmospheric fronts become persistent near SST fronts. Nevertheless, Masunaga et al. (2020) argue that atmospheric convection and associated diabatic heating can be important. The thermal damping and strengthening mechanism (Parfitt and Seo 2018) and an orographic effect can also play important roles. We will conduct detailed investigation using frontogenetical function (Hoskins 1982; Masunaga et al. 2015) and sensitivity experiments with 
C5 1993-01-07-12 - 1993-01-08-12
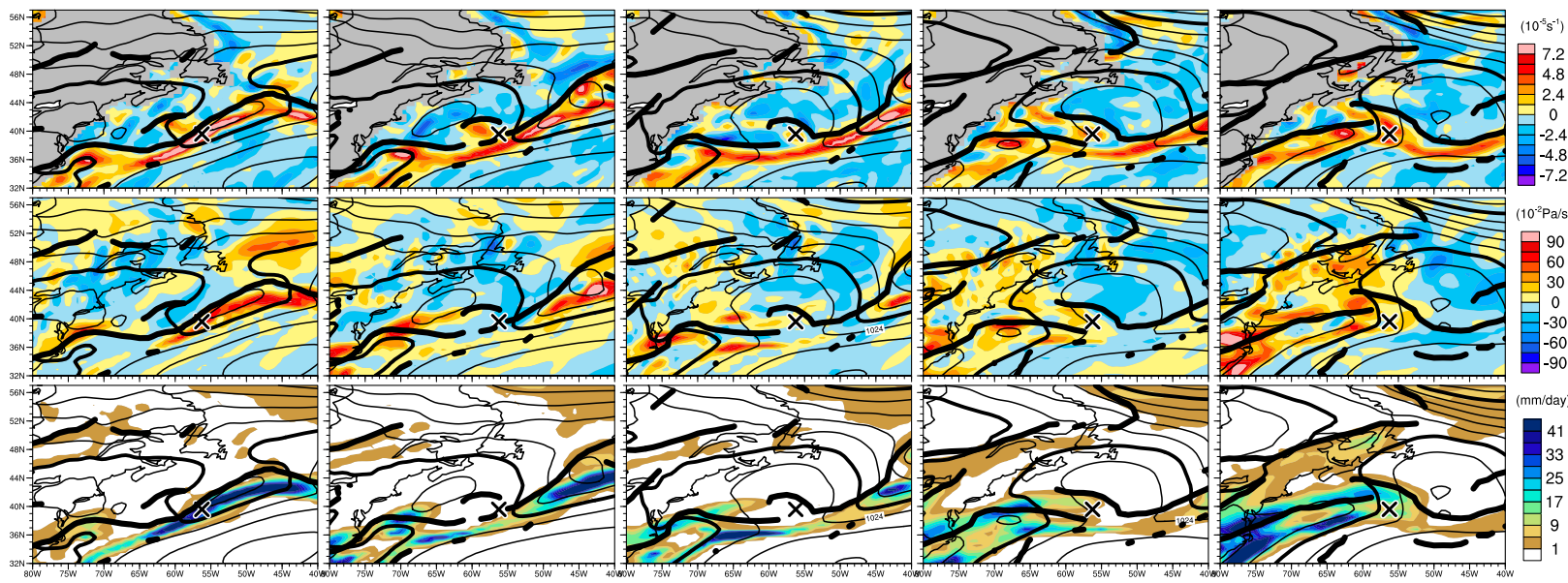

FIG. 11. As in Fig. 9, but from 1200 UTC 7 Jan 1993.

atmospheric models to clarify the roles of SST fronts. We will also explore the processes shaping the timemean frontal-scale atmospheric structure in summer. We finally note that our findings need to be verified by other atmospheric reanalysis data produced with highresolution SST data such as the ERA-Interim (Dee et al. 2011) for the period after 2001 (Masunaga et al. 2015) and ERA5 (Hersbach et al. 2020).

$$
\mathrm{N}=143(17.1 \%)
$$
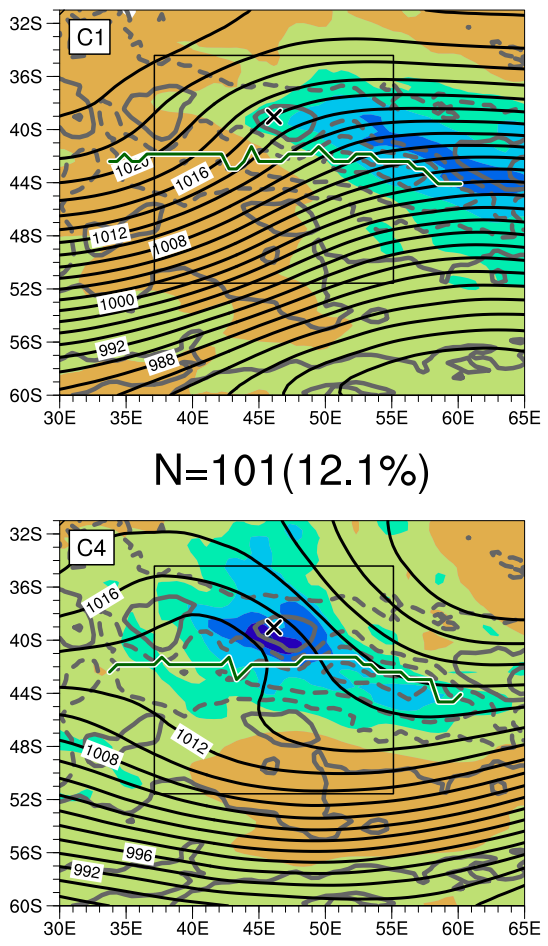

$$
\mathrm{N}=108(12.9 \%)
$$

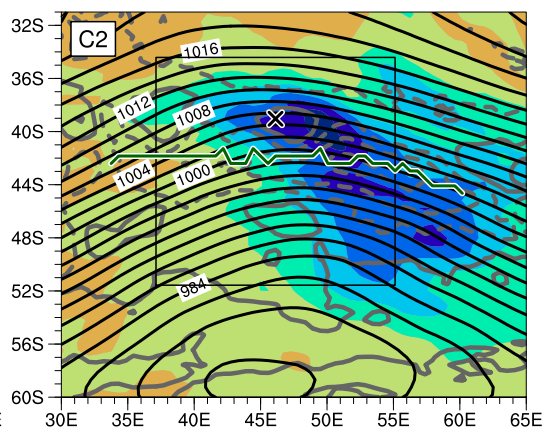

$$
\mathrm{N}=142(17.0 \%)
$$

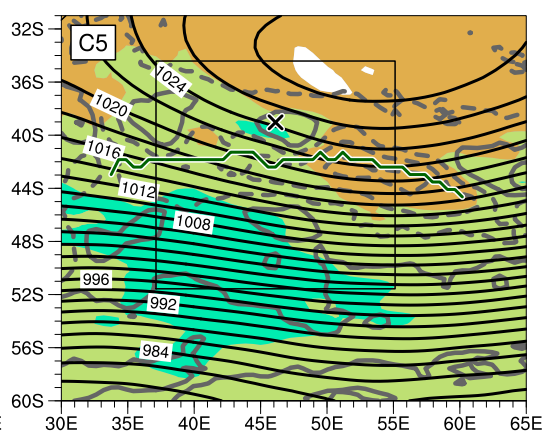

$\mathrm{N}=179(21.4 \%)$

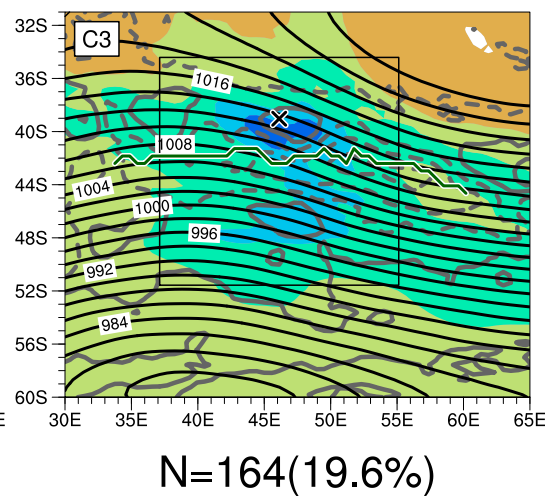

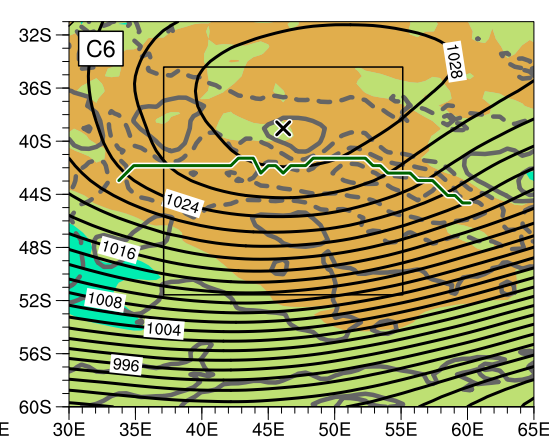

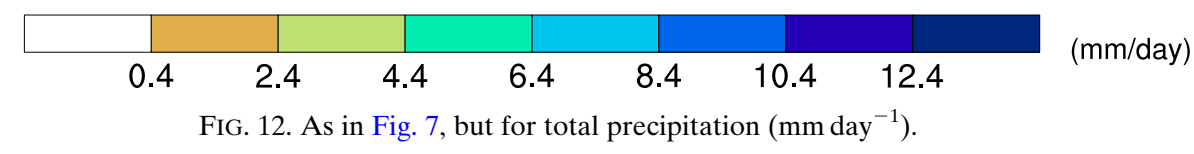


C1 1994-07-08-06 - 1994-07-09-06

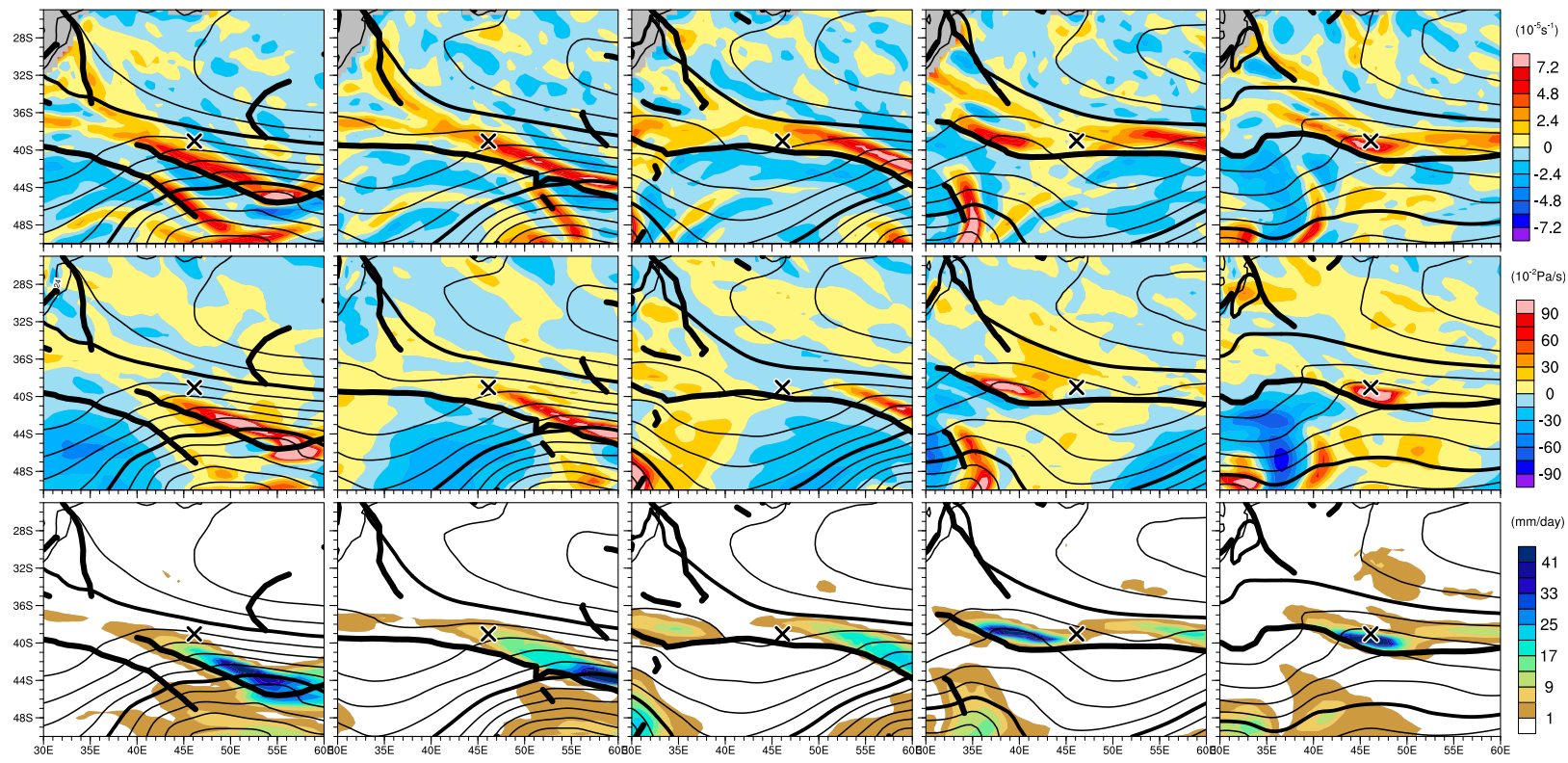

FIG. 13. As in Fig. 9, but from 0600 UTC 8 Jul 1994 for the Agulhas Return Current region. The cross marks are as in Fig. 7.

Acknowledgments. We thank the two anonymous reviewers for their sound criticism and constructive comments that helped improve the manuscript. We also thank Drs. H. Kamahori, C. Kobayashi, and Y. Ota for their effort in producing JRA-55CHS. This study is supported in part by the Japan Society for the Promotion of Science through Grants-in-Aid for Scientific Research 16H01844 and JP19H05702 (on Innovative Areas 6102), by the Japanese Ministry of Education, Culture, Sports, Science and Technology

C5 2006-07-14-18 - 2006-07-15-18
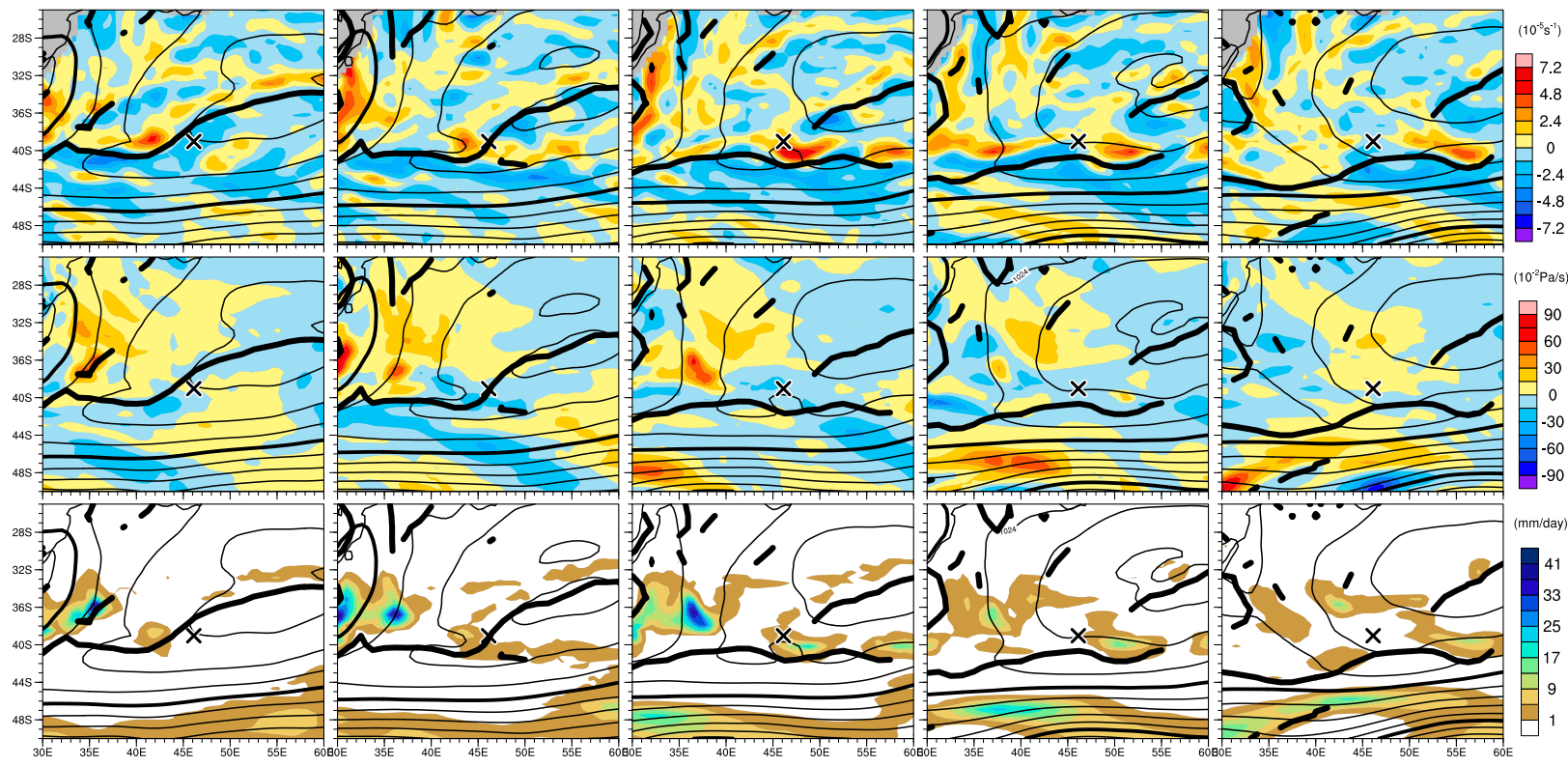

FIG. 14. As in Fig. 13, but from 1800 UTC 14 Jul 2006. 

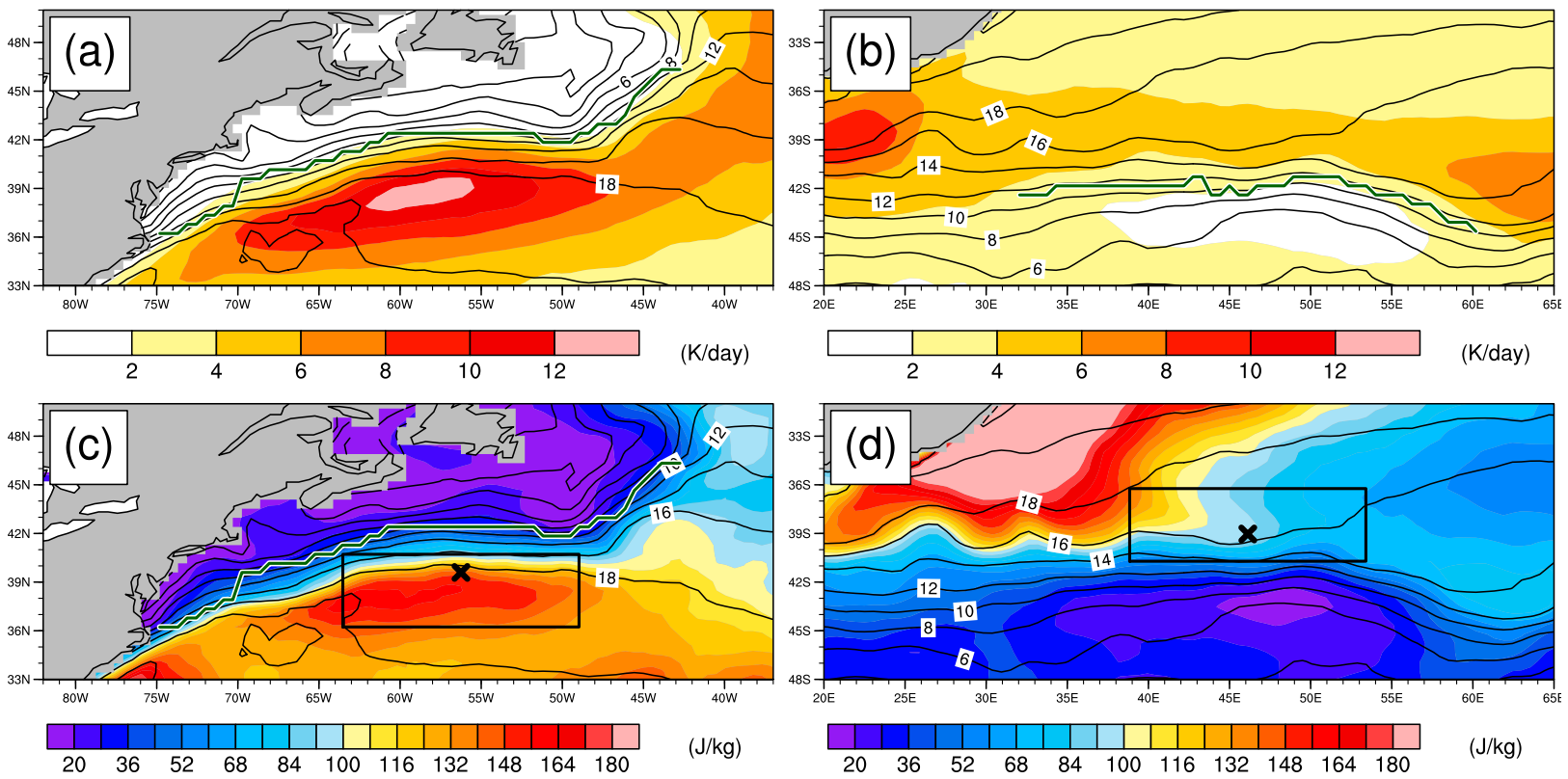

FIG. 15. As in Fig. 2, but for SST (contoured every $2^{\circ} \mathrm{C}$ ) and (a) convective heating rate at the 850-hPa level (shaded; K day ${ }^{-1}$ ) and (c) convective available potential energy (CAPE) evaluated for the lowest model level ( $\mathrm{J} \mathrm{kg}^{-1}$ ) for January over the Gulf Stream region. (b),(d) As in (a) and (c), respectively, but for July over the Agulhas Return Current region. The cross marks in (c) and (d) indicate the target points used for the cluster analysis and the rectangles the domains used for averaging in Fig. 16.

(MEXT) through the Arctic Challenge for Sustainability (ArCS) Program, by the Japanese Ministry of Environment through the Environment Research and Technology Development Fund 2-1904, and by the Japan Science and Technology Agency through Belmont Forum CRA "InterDec". This work is also supported by MEXT as "Program for Promoting Researches on the Supercomputer Fugaku“ (Large Ensemble Atmospheric and Environmental Prediction for Disaster Prevention and Mitigation), and JSPS KAKENHI 19H05703. RM is partly supported by Grant-inAid for JSPS Research Fellow. The NCAR Command Language (NCL) software package was used for drawing the figures and estimating CAPE. This is International Pacific Research Center Publication Number 1469 and School of Ocean and Earth Science and Technology Publication Number 11115.

\section{APPENDIX}

\section{Sensitivity of Atmospheric Front Statistics to Specific Detection Methods}

Previous studies have argued that atmospheric front statistics can be rather sensitive to detection methods and thresholds (e.g., Thomas and Schultz 2019a,b). In this appendix, we verify the robustness of our findings by using different detection methods and thresholds. With the TFP method based on $\theta_{e}$ with $1.25^{\circ}$ resolution, we have confirmed that the results are insensitive to the thresholds in $\left|\nabla \theta_{e}\right|$. Furthermore, the results are essentially unchanged when the $0.56^{\circ}$-resolution data are used with horizontal smoothing as proposed by Jenkner et al. (2010). We also have confirmed that the " $F$ diagnostic," where vorticity as well as temperature gradients are taken into consideration (Parfitt et al. 2017), yields overall the same features as well, although the persistent fronts are less clearly represented. The TFP method using potential temperature $(\theta)$ in place of $\theta_{e}$ also yields climatological local maxima of frontal frequency along the WBCs as in Fig. 5 with the threshold of $|\nabla \theta| \geq 1 \mathrm{~K}(100 \mathrm{~km})^{-1}$. Although the corresponding signature becomes less clear with greater thresholds along the ARC, the results are overall insensitive to the thresholds for the GS and KE regions.

Nevertheless, we do not deny the possibility that some other detection methods may yield inconsistent results. For instance, the "wind method" (Simmonds et al. 2012) may not well detect the persistent fronts as it may not be particularly suited for capturing zonally oriented fronts (Schemm et al. 2015). At this moment, we would suggest that $\theta_{e}$ is the best choice to identify impacts of the SST fronts, in recognition of locally enhanced sensible and moisture fluxes on their warmer sides. Still, in addition to temperature gradients, such additional factors as humidity gradients or vorticity may 

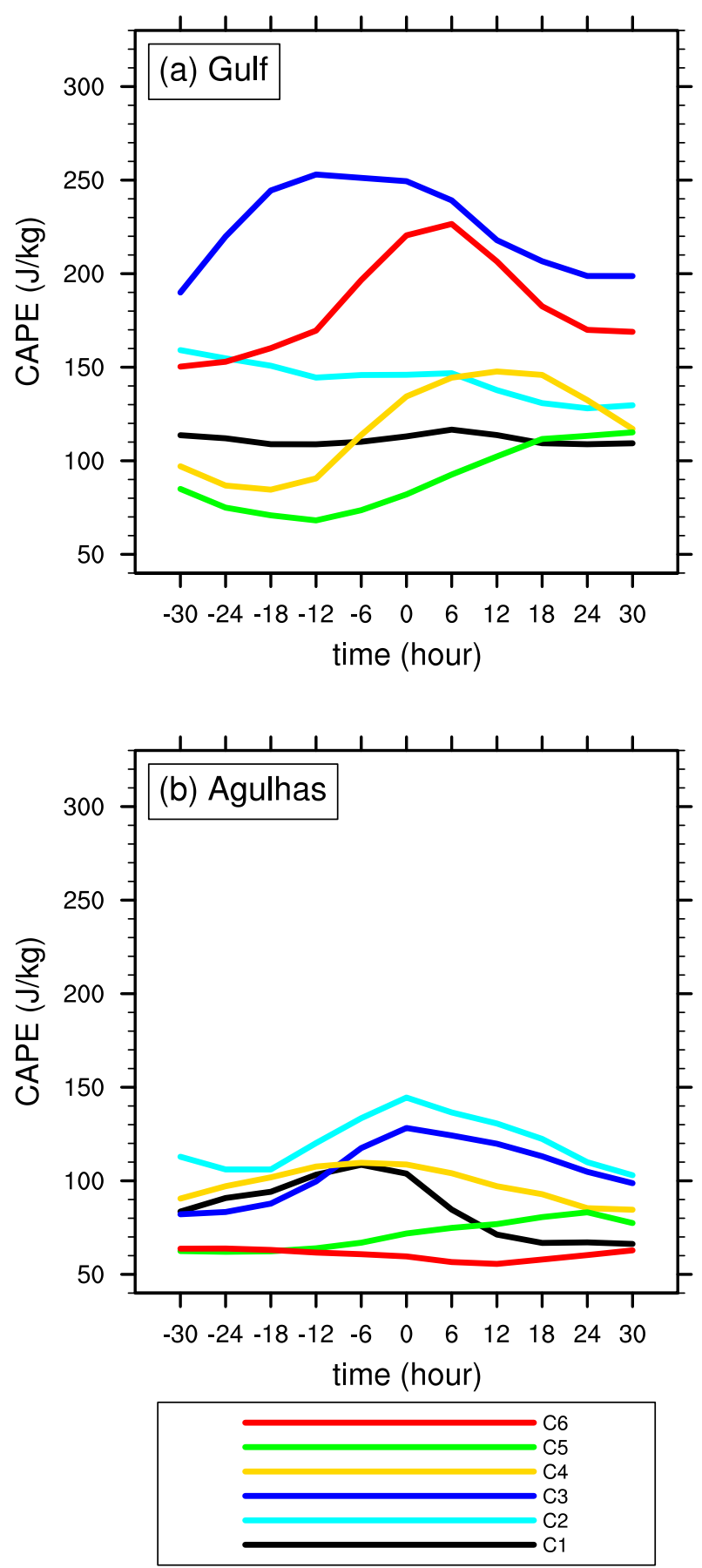

FIG. 16. As in Fig. 10, but for convective available potential energy (CAPE; $\mathrm{J} \mathrm{kg}^{-1}$ ) averaged over the rectangular domains indicated in Fig. 15.

be required to better capture the rather weak influence from the ARC. Since the sensitivity of the frontal detection to temporal resolution of atmospheric data has not been examined, our results might need to be interpreted with caution.

\section{REFERENCES}

Bolton, D., 1980: The computation of equivalent potential temperature. Mon. Wea. Rev., 108, 1046-1053, https://doi.org/ 10.1175/1520-0493(1980)108<1046:TCOEPT > 2.0.CO;2.

Dee, D. P., and Coauthors, 2011: The ERA-Interim reanalysis: Configuration and performance of the data assimilation system. Quart. J. Roy. Meteor. Soc., 137, 553-597, https://doi.org/10.1002/qj.828.

Frenger, I., N. Gruber, R. Knutti, and M. Münnich, 2013: Imprint of Southern Ocean eddies on winds, clouds and rainfall. Nat. Geosci., 6, 608-612, https://doi.org/10.1038/ngeo1863.

Hayes, S. P., M. J. McPhaden, and J. M. Wallace, 1989: The influence of sea-surface temperature on surface wind in the eastern equatorial Pacific: Weekly to monthly variability. J. Climate, 2 , 1500-1506, https://doi.org/10.1175/1520-0442(1989)002<1500: TIOSST $>2.0 . \mathrm{CO} ; 2$.

Hersbach, H., and Coauthors, 2020: The ERA5 global reanalysis. Quart. J. Roy. Meteor. Soc., 146, 1999-2049, https://doi.org/ 10.1002/qj.3803.

Hewson, T. D., 1998: Objective fronts. Meteor. Appl., 5, 37-65, https://doi.org/10.1017/S1350482798000553.

Hoskins, B. J., 1982: The mathematical theory of frontogenesis. Annu. Rev. Fluid Mech., 14, 131-151, https://doi.org/10.1146/ annurev.fl.14.010182.001023.

Hotta, D., and H. Nakamura, 2011: On the significance of the sensible heat supply from the ocean in the maintenance of the mean baroclinicity along storm tracks. J. Climate, 24, 33773401, https://doi.org/10.1175/2010JCLI3910.1.

Jenkner, J., M. Sprenger, I. Schwenk, C. Schwierz, S. Dierer, and D. Leuenberger, 2010: Detection and climatology of fronts in a high-resolution model reanalysis over the Alps. Meteor. Appl., 17 (1), 1-18, https://doi.org/10.1002/MET.142.

Kawase, H., Y. Takeuchi, T. Sato, and F. Kimura, 2006: Precipitable water vapor around orographically induced convergence line. SOLA, 2, 25-28, https://doi.org/10.2151/ SOLA.2006-007.

Kilpatrick, T., N. Schneider, and B. Qiu, 2016: Atmospheric response to a midlatitude SST front: Alongfront winds. J. Atmos. Sci., 73, 3489-3509, https://doi.org/10.1175/JAS-D-15-0312.1.

Kuwano-Yoshida, A., S. Minobe, and S.-P. Xie, 2010: Precipitation response to the Gulf Stream in an atmospheric GCM. J. Climate, 23, 3676-3698, https://doi.org/10.1175/2010JCLI3261.1.

Lindzen, R. S., and S. Nigam, 1987: On the role of sea surface temperature gradients in forcing low-level winds and convergence in the tropics. J. Atmos. Sci., 44, 2418-2436, https://doi.org/ 10.1175/1520-0469(1987)044<2418:OTROSS >2.0.CO;2.

Liu, W. T., X. Xie, and P. P. Niiler, 2007: Ocean-atmosphere interaction over Agulhas extension meanders. J. Climate, 20, 5784-5797, https://doi.org/10.1175/2007JCLI1732.1.

Masunaga, R., H. Nakamura, T. Miyasaka, K. Nishii, and Y. Tanimoto, 2015: Separation of climatological imprints of the Kuroshio Extension and Oyashio fronts on the wintertime atmospheric boundary layer: Their sensitivity to SST resolution prescribed for atmospheric reanalysis. J. Climate, 28, 1764-1787, https://doi.org/10.1175/JCLI-D-14-00314.1.

$\longrightarrow,-,-, \ldots$, and B. Qiu, 2016: Interannual modulations of oceanic imprints on the wintertime atmospheric boundary layer under the changing dynamical regimes of the Kuroshio Extension. J. Climate, 29, 3273-3296, https://doi.org/10.1175/JCLI-D-15-0545.1. ,-- H. Kamahori, K. Onogi, and S. Okajima, 2018: JRA55CHS: An atmospheric reanalysis produced with highresolution SST. SOLA, 14, 6-13, https://doi.org/10.2151/ SOLA.2018-002. 
,--1, B. Taguchi, and T. Miyasaka, 2020: Processes shaping the frontal-scale time-mean surface wind convergence patterns around the Kuroshio Extension in winter. J. Climate, 33, 3-25, https://doi.org/10.1175/JCLI-D-19-0097.1.

Minobe, S., A. Kuwano-Yoshida, N. Komori, S. P. Xie, and R. J. Small, 2008: Influence of the Gulf Stream on the troposphere. Nature, 452, 206-209, https://doi.org/10.1038/nature06690.

_- M. Miyashita, A. Kuwano-Yoshida, H. Tokinaga, and S. P. Xie, 2010: Atmospheric response to the Gulf Stream: Seasonal variations. J. Climate, 23, 3699-3719, https://doi.org/10.1175/ 2010JCLI3359.1.

Miyamoto, A., H. Nakamura, and T. Miyasaka, 2018: Influence of the subtropical high and storm track on low-cloud fraction and its seasonality over the south Indian Ocean. J. Climate, 31, 4017-4039, https://doi.org/10.1175/JCLI-D-17-0229.1.

Nakamura, H., and A. Shimpo, 2004: Seasonal variations in the Southern Hemisphere storm tracks and jet streams as revealed in a reanalysis dataset. J. Climate, 17, 1828-1844, https:// doi.org/10.1175/1520-0442(2004)017<1828:SVITSH>2.0.CO;2.

_ T. Sampe, Y. Tanimoto, and A. Shimpo, 2004: Observed associations among storm tracks, jet streams and midlatitude oceanic fronts. Earth's Climate: The Ocean-Atmosphere Interaction, Geophys. Monogr., Vol. 147, Amer. Geophys. Union, 329-345.

_ A. Shimpo, A. Goto, W. Ohfuchi, and S.-P. Xie, 2008: On the importance of midlatitude oceanic frontal zones for the mean state and dominant variability in the tropospheric circulation. Geophys. Res. Lett., 35, L15709, https://doi.org/10.1029/ 2008GL034010.

Neu, U., and Coauthors, 2013: IMILAST: A community effort to intercompare extratropical cyclone detection and tracking algorithms. Bull. Amer. Meteor. Soc., 94, 529-547, https:// doi.org/10.1175/BAMS-D-11-00154.1.

Nkwinkwa Njouodo, A. S., S. Koseki, N. Keenlyside, and M. Rouault, 2018: Atmospheric signature of the Agulhas Current. Geophys. Res. Lett., 45, 5185-5193, https://doi.org/ 10.1029/2018GL077042.

Nonaka, M., H. Nakamura, B. Taguchi, N. Komori, A. KuwanoYoshida, and K. Takaya, 2009: Air-sea heat exchanges characteristic of a prominent midlatitude oceanic front in the south Indian Ocean as simulated in a high-resolution coupled GCM. J. Climate, 22, 6515-6535, https://doi.org/10.1175/2009JCLI2960.1.

Ogawa, F., and T. Spengler, 2019: Prevailing surface wind direction during air-sea heat exchange. J. Climate, 32, 5601-5617, https://doi.org/10.1175/JCLI-D-18-0752.1.

—, H. Nakamura, K. Nishii, T. Miyasaka, and A. KuwanoYoshida, 2012: Dependence of the climatological axial latitudes of the tropospheric westerlies and storm tracks on the latitude of an extratropical oceanic front. Geophys. Res. Lett., 39, L05804, https://doi.org/10.1029/2011GL049922.

O'Neill, L. W., D. B. Chelton, and S. K. Esbensen, 2003: Observations of SST-induced perturbations of the wind stress field over the Southern Ocean on seasonal timescales. J. Climate, 16, 23402354, https://doi.org/10.1175/2780.1.

,,--- , and F. J. Wentz, 2005: High-resolution satellite measurements of the atmospheric boundary layer response to SST variations along the Agulhas Return Current. J. Climate, 18, 2706-2723, https://doi.org/10.1175/JCLI3415.1.
— T. Haack, D. B. Chelton, and E. Skyllingstad, 2017: The Gulf Stream convergence zone in the time-mean winds. J. Atmos. Sci., 74, 2383-2412, https://doi.org/10.1175/JAS-D-16-0213.1.

Parfitt, R., and A. Czaja, 2016: On the contribution of synoptic transients to the mean atmospheric state in the Gulf Stream region. Quart. J. Roy. Meteor. Soc., 142, 1554-1561, https:// doi.org/10.1002/qj.2689.

- and H. Seo, 2018: A new framework for near-surface wind convergence over the Kuroshio Extension and Gulf Stream in wintertime: The role of atmospheric fronts. Geophys. Res. Lett., 45, 9909-9918, https://doi.org/10.1029/2018GL080135.

— A. Czaja, S. Minobe, and A. Kuwano-Yoshida, 2016: The atmospheric frontal response to SST perturbations in the Gulf Stream region. Geophys. Res. Lett., 43, 2299-2306, https:// doi.org/10.1002/2016GL067723.

,$- \ldots$, and H. Seo, 2017: A simple diagnostic for the detection of atmospheric fronts. Geophys. Res. Lett., 44, 4351-4358, https://doi.org/10.1002/2017GL073662.

Sampe, T., H. Nakamura, A. Goto, and W. Ohfuchi, 2010: Significance of a midlatitude SST frontal zone in the formation of a storm track and an eddy-driven westerly jet. J. Climate, $\mathbf{2 3}$, 1793-1814, https://doi.org/10.1175/2009JCLI3163.1.

Schemm, S., I. Rudeva, and I. Simmonds, 2015: Extratropical fronts in the lower troposphere-Global perspectives obtained from two automated methods. Quart. J. Roy. Meteor. Soc., 141, 1686-1698, https://doi.org/10.1002/qj.2471.

Schneider, N., and B. Qiu, 2015: The atmospheric response to weak sea surface temperature fronts. J. Atmos. Sci., 72, 3356-3377, https://doi.org/10.1175/JAS-D-14-0212.1.

Simmonds, I., K. Keay, and J. A. T. Bye, 2012: Identification and climatology of Southern Hemisphere mobile fronts in a modern reanalysis. J. Climate, 25, 1945-1962, https://doi.org/ 10.1175/JCLI-D-11-00100.1.

Small, R. J., and Coauthors, 2008: Air-sea interaction over ocean fronts and eddies. Dyn. Atmos. Oceans, 45, 274-319, https:// doi.org/10.1016/j.dynatmoce.2008.01.001.

Taguchi, B., H. Nakamura, M. Nonaka, and S. P. Xie, 2009: Influences of the Kuroshio/Oyashio extensions on air-sea heat exchanges and storm-track activity as revealed in regional atmospheric model simulations for the 2003/04 cold season. J. Climate, 22, 6536-6560, https://doi.org/10.1175/2009JCLI2910.1.

Thomas, C. M., and D. M. Schultz, 2019a: What are the best thermodynamic quantity and function to define a front in gridded model output? Bull. Amer. Meteor. Soc., 100, 873-895, https://doi.org/10.1175/BAMS-D-18-0137.1.

, and —, 2019b: Global climatologies of fronts, airmass boundaries, and airstream boundaries: Why the definition of "front" matters. Mon. Wea. Rev., 147, 691-717, https://doi.org/ 10.1175/MWR-D-18-0289.1.

Tokinaga, H., Y. Tanimoto, and S. P. Xie, 2005: SST-induced surface wind variations over the Brazil-Malvinas confluence: Satellite and in situ observations. J. Climate, 18, 3470-3482, https://doi.org/10.1175/JCLI3485.1.

Wallace, J. M., T. P. Mitchell, and C. Deser, 1989: The influence of seasurface temperature on surface wind in the eastern equatorial Pacific: Seasonal and interannual variability. J. Climate, 2, 1492-1499, https:// doi.org/10.1175/1520-0442(1989)002<1492:TIOSST>2.0.CO;2. 